\title{
Autoregulation in Resistance Training for Lower Limb Tendinopathy: A Potential Method for Addressing Individual Factors, Intervention Issues and Inadequate Outcomes
}

Ian Burton MSc, CSCS

Physiotherapist, Angus HSCP, NHS Tayside, Dundee, United Kingdom

Please cite as: Burton, I. (2020). Autoregulation in Resistance Training for Lower Limb Tendinopathy: A Potential Method for Addressing Individual Factors, Intervention Issues and Inadequate Outcomes.

SportRxiv doi: 10.31236/osf.io/zxvuy

\section{ABSTRACT}

Musculoskeletal disorders such as tendinopathy are having an increasing burden on society and health systems. Tendinopathy is responsible for up to $30 \%$ of musculoskeletal disorders, having a high incidence in athletes and the general population. Although resistance training has shown short-term effectiveness for treating lower limb tendinopathy, more comprehensive exercise protocols and progression methods are required due to poor long-term outcomes. The most common resistance training protocols are pre-determined and standardised, which 
presents significant limitations. Current standardized protocols do not adhere to scientific resistance training principles and do not consider individual factors or take the importance of individualised training into account. Resistance training programs in tendinopathy are currently not achieving required intensity and dosage, leading to high recurrence rates. Therefore, better methods for individualising and progressing resistance training are required to improve outcomes. One potential method is autoregulation, which allows individuals to progress training at their own rate, taking individual factors into account. Despite being found effective for increasing strength in healthy athletes, autoregulation methods have not been investigated in tendinopathy. The purpose of this article was threefold: first to give an overview of individual factors in tendinopathy and current resistance training protocols in tendinopathy and their limitations. Secondly, to give an overview of the history, methods and application of autoregulation strategies both in sports performance and physiotherapy. Finally, a theoretical adaptation of a tendinopathy resistance training protocol with autoregulation methods is presented, providing an example of how the method could be implemented in clinical practice or future research.

Keywords: Exercise; Resistance training; Autoregulation; Tendinopathy; Musculoskeletal Diseases

\section{Key points}

1. Specific resistance training protocols have been widely adopted in clinical practice and research for tendinopathy rehabilitation for over 20 years. However, protocols remain largely underdeveloped, and have evolved little since their initial development. Current protocols lack adherence to the scientific principles of progressive resistance training, perhaps contributing to their poor long-term outcomes. Increasing attention to the application of the scientific principles that underlie adaptation to manipulating the exercises stimulus in a progressive manner could improve training prescription and outcomes in tendinopathy.

2. A significant range of physical, genetic and psychological individual factors have been identified across tendinopathy patients, resulting in a largely 
heterogenous population. Tendinopathies also present on various stages of a continuum, with each stage potentially responding differently to the training stimulus. These factors can impact upon individual performance, adaptation, adherence and response to resistance training interventions. Therefore, protocols should be personalised and individually modified as opposed to the current pre-determined and standardised protocols.

3. Autoregulation may represent a potential method of personalising tendinopathy resistance training protocols, allowing for modification based on individual training response across the tendinopathy continuum. Future research should examine the efficacy of such an approach, like the example presented here, as a potential method of improving outcomes of common tendinopathy resistance training interventions.

\section{Introduction}

Recently published studies have highlighted how musculoskeletal disorders are collectively a leading global cause of disability and pain, impacting on a broad demographic spectrum of society [1-5]. Tendinopathy accounts for up to $50 \%$ of all musculoskeletal disorders and is often associated with chronic pain, decreased physical function, and reduced participation in activities [6-7]. Although the aetiology of tendinopathy remains not fully understood, it is known to be caused by repetitive tendon microtrauma and failed tendon healing [8-12]. This disrupted healing process manifests as increased tendon thickness, neovascularization, and incidence of calcium deposits or calcification [13-14]. The previously used term 'tendinitis' referred to an inflammatory process, and while inflammatory cells may be present, the term tendinopathy has been adopted to reflect the often degenerative and non-inflammatory nature of the disorder [15-17]. Athletes exposed to frequent loading through training and competition are particularly susceptible to developing tendinopathy due to repeated tendon stress and overloading [18]. Patellar tendinopathy has had a reported prevalence of $45 \%$ in elite volleyball players and $32 \%$ in elite basketball players [19]. Achilles tendinopathy has a lifetime risk of $52 \%$ in elite runners, with an incidence of $24 \%$ among competitive athletes and $18 \%$ among young athletes compared to $5.9 \%$ in sedentary populations [20]. 
A range of common treatments are used in tendinopathy rehabilitation including anti-inflammatory medications, corticosteroid injections, low-level-laser therapy, ultrasound, platelet-rich-plasma injections, prolotherapy, glycerol trinitrate patches, manual therapy, shockwave therapy and exercise [21-22]. Exercise is the most common and recommended treatment option, with heavy slow resistance training and eccentric strengthening interventions having positive outcomes for various lower limb tendinopathies such as plantar heel pain, Achilles, and patellar tendinopathy [23-24]. Despite positive short-term outcomes, longterm outcomes remain poor, with up to $40 \%$ of patients having symptoms two years after resistance training interventions [25]. Recent evidence suggests current resistance training interventions are not achieving the required loading dosages in order to stimulate mechanobiological changes, such as strength increases and tendon changes [26]. Current resistance training interventions may not follow scientific training principles, and may require more accurate modification of training variables, such as frequency, intensity and volume [19]. A shift to a more scientifically supported training model, such as periodization models used in training athletes, may improve outcomes [27]. Autoregulation is a concept of training derived from periodization models, which relates to manipulating training variables based on an individual's circumstances such as response to training and daily readiness to train [28].

Recently, many individual factors have been identified in tendinopathy, highlighting the heterogeneity of this patient population [29]. Therefore, standardised resistance training in which all patients receive the same rigid training protocol, is likely not appropriate. The implementation of autoregulation methods within tendinopathy resistance training may achieve individualisation of training loads and dosage, which may maximise clinical outcomes compared to following standardized protocols not tailored to the individual [30]. However, to the authors knowledge, autoregulation methods within tendinopathy resistance training interventions has not previously been investigated. Therefore, the purpose of this review is to synthesize the current research on resistance training interventions for lower limb tendinopathies, their limitations and potential autoregulation strategies. The review will begin with an overview of individual factors and resistance training protocols in tendinopathy before providing an 
overview of the theory and implementation of autoregulation methods. Finally, an overview of the potential application of autoregulation methods will be applied to a current tendinopathy protocol, allowing for potential clinical application, which may have the potential to improve clinical outcomes.

\section{Individual factors}

Tendinopathies are challenging to treat and are considered to have a multifactorial pathogenesis resulting from extrinsic and intrinsic factors [31-32]. Factors such as abnormal or repeated tendon loading combined with genetic, biological and cellular variations may lead to tendon changes and damage [33]. Although considered a condition common in athletes and the physically active, tendinopathies are also commonly seen in sedentary patients and the elderly [34]. Gender differences may also present, with Achilles tendon injuries for example being more common in males than females [35]. Tendinopathies in different locations such as the upper and lower limbs, present different pathophysiological and aetiological circumstances which will require individual treatment approaches, despite treatment often being standardised across all tendinopathies [36].

Individual variability in biomechanics, such as anatomical differences, malalignment, neuromuscular capacity, weakness or strength, foot structure, flexibility, repeated training errors, movement kinetics and kinematics may lead to repetitive, excessive or compressive loading on tendons [37-40]. In patellar tendinopathy, up to 37 different individual biomechanical risk variables have been identified in relation to jump-landing strategy alone [41]. The identified external risk factors may have a complex interplay with individual intrinsic and biological factors such as, age, gender, bodyweight, hormones, genetics, height, prior tendon injury and health conditions such as obesity, diabetes, hyperlipidaemia, rheumatological conditions and [42-44]. Environmental factors may also contribute to individual tendinopathy risk, including daily activities, smoking, alcohol consumption, poor nutrition or sleep habits, physically demanding workplace, stress, inappropriate footwear and medications such as corticosteroids, 
statins, aromatase inhibitors, and fluoroquinolone antibiotics [45-46]. Individual differences and factors such as loading capacity and tolerance, motor control, education, beliefs, exercise types and preferences, psychosocial and contextual factors have also been shown to be important factors related to individual response to rehabilitation and treatment outcomes [47-61].

Andia and Maffulli [62] highlighted that response to tendinopathy treatment interventions are strictly individual and can be inherent to the genetic background, demography, immune status, microbiota function, associated metabolic diseases, systemic drugs or local anesthetics, characteristics and stage of recipient tissue, including inflammation, angiogenic state, and cellularity. Positive responses to resistance training are influenced by a multitude of individual factors including fitness level, training history, nutritional intake, psychological and social states, sleep and recovery, age, weight, and overall training workload [63]. However, many of these factors can prove difficult to evaluate in clinical practice [64], with a thorough clinical assessment of each individual and their personal factors required prior to prescribing resistance training interventions [65]. The wideranging variety of potential factors involved in development, progression and rehabilitation of tendinopathy may lead to a highly diverse and broad range of potential cellular responses and ultimately a broad pathological spectrum of disease, leading to a vastly heterogenous tendinopathic patient population.

Due to the plethora of potential individual patient characteristics and risk factors involved in any tendinopathy, their presentation is highly heterogenous in nature, with a multitude of potential factors contributing to triggering the onset of tendinopathy [29]. Individual patient characteristics such as age, gender and genetics can interplay with lifestyle habits such as smoking, alcohol consumption and physical activity levels, leading to a diverse spectrum of potential tendinopathy risk and onset factors. All cases of tendinopathy do not clinically present uniformly, with each individual case of tendinopathy having a varying degree of symptomatic presentation, such as pain, swelling, weakness and functional ability. Pain experienced from tendinopathy is not always associated with tissue damage, suggesting that other neurophysiological mechanisms may 
be involved [66-68]. Central nervous system hypersensitivity and the role of pain central sensitization has recently emerged as a potential contributing factor, which can vary in presentation among individuals [69-72].

Although the importance of an individualised approach to a heterogenous tendinopathy population has been repeatedly stressed in the tendinopathy literature, it is clearly a limitation when developing studies, due to the effort and the need to homogenize samples. However, there is a special need to make progress in the knowledge of treating patients with tendinopathy even when perfect homogeneity is not possible [19]. The heterogeneous presentation of tendinopathies means that a 'one size fits all' treatment approach may be inappropriate and related to the poor long-term treatment outcomes [73]. The Achilles tendon for example can experience positive adaptation when exposed to strains within a specific range or 'sweet spot', which depends on many factors known to differ between individuals, requiring treatment interventions that account for these interindividual differences [74]. Physiotherapists have reported having to use complex clinical reasoning to adapt eccentric training research protocols for individual patients. For example, the need to vary eccentric loading protocols in patients where pain prevented adherence to published protocols by substituting with mixed concentric/eccentric or isometric loading initially. To assist this process, future research could focus on variables within the eccentric training programme that could affect its efficacy, such as speed of exercises, duration, rate of progression and loading, chronicity and severity of the condition [75].

As the etiology of tendinopathy is multifactorial, rehabilitation should be focused on identifying the multiple risk factors that affect a specific individual [76]. It could be considered a disservice to the patient if the factors contributing to the development of their tendinopathy are not addressed [77]. It is important to consider that each individual will respond differently to rehabilitation, and each program must be tailored to the individual, with 'Recipe' approaches to tendinopathy rehabilitation failing to capitalize on the potential for recovery [7879]. The individual's needs must be addressed in the rehabilitation programme, which was a prominent aspect emphasised in a recent e-Delphi survey and 
included in a patellar tendinopathy framework. The results quantified three central aspects, namely functional abilities, individualised rehabilitation and load tolerance, to form the foundation of the rehabilitation framework [80]. Factors relevant when accessing, adapting, and applying training protocols to the patient include mapping information gathered from careful history taking to pathophysiological knowledge and likely treatment responses to enable clinical decisions that utilize interventions in an individualized way [81]. Comorbidities, symptom development, previous interventions outcomes, patient beliefs, psychosocial and cultural factors, likely tissue demands, and others may radically influence intervention outcomes. Different tendinopathies and pathological tendon states combined with individual circumstances require an individulaised treatment approach which must be applied to progressive resistance training interventions [81].

Despite the necessity of addressing individual factors in tendinopathy, they are often not considered in rehabilitation, with treatment offered to a young elite male athlete often the same as that for a postmenopausal woman [82]. Cook and Purdam [82] proposed that tendinopathy pathology is not absolute and presents on a continuum, with three distinct stages, with each having implications for treatment. The staging model acknowledges the heterogeneity of tendinopathy presentation, with the three phases being 1 ) early reactive tendinopathy due to acute overload, 2) tendon disrepair after failed healing responses and 3) degenerative tendinopathy with permanent structural and cellular damage [83]. The individual tendinopathy risk factors discussed earlier may play a role in altering progression throughout this continuum and will likely contribute to individual treatment response [84]. The continuum model suggests that management may be optimised by tailoring interventions to the stage of pathology and targeting the primary driver and inter-related alterations. While exercise is considered fundamental to management, a plethora of other tendinopathy treatment interventions exist which increases the complexity of the clinical decision-making process. Tendinopathy is a heterogeneous clinical presentation due to the variable change in cellular matrix structure, pain and dysfunction between individuals [85-86]. Phenotyping of patients based on structure, pain, dysfunction and load capacity may allow the clinician to direct appropriate 
treatments at the critical limiting factors [83]. A recent model proposed by Steinmann et al. [29] demonstrates the complex interplay of individual factors in tendinopathy pathogenesis and how they relate to the tendon continuum model (Figure 1). A further step would be to integrate individualised treatment strategies into this model, at each pathology stage.

Figure 1: Individual factors and tendinopathy pathology continuum (Steinmann et al. 2020)

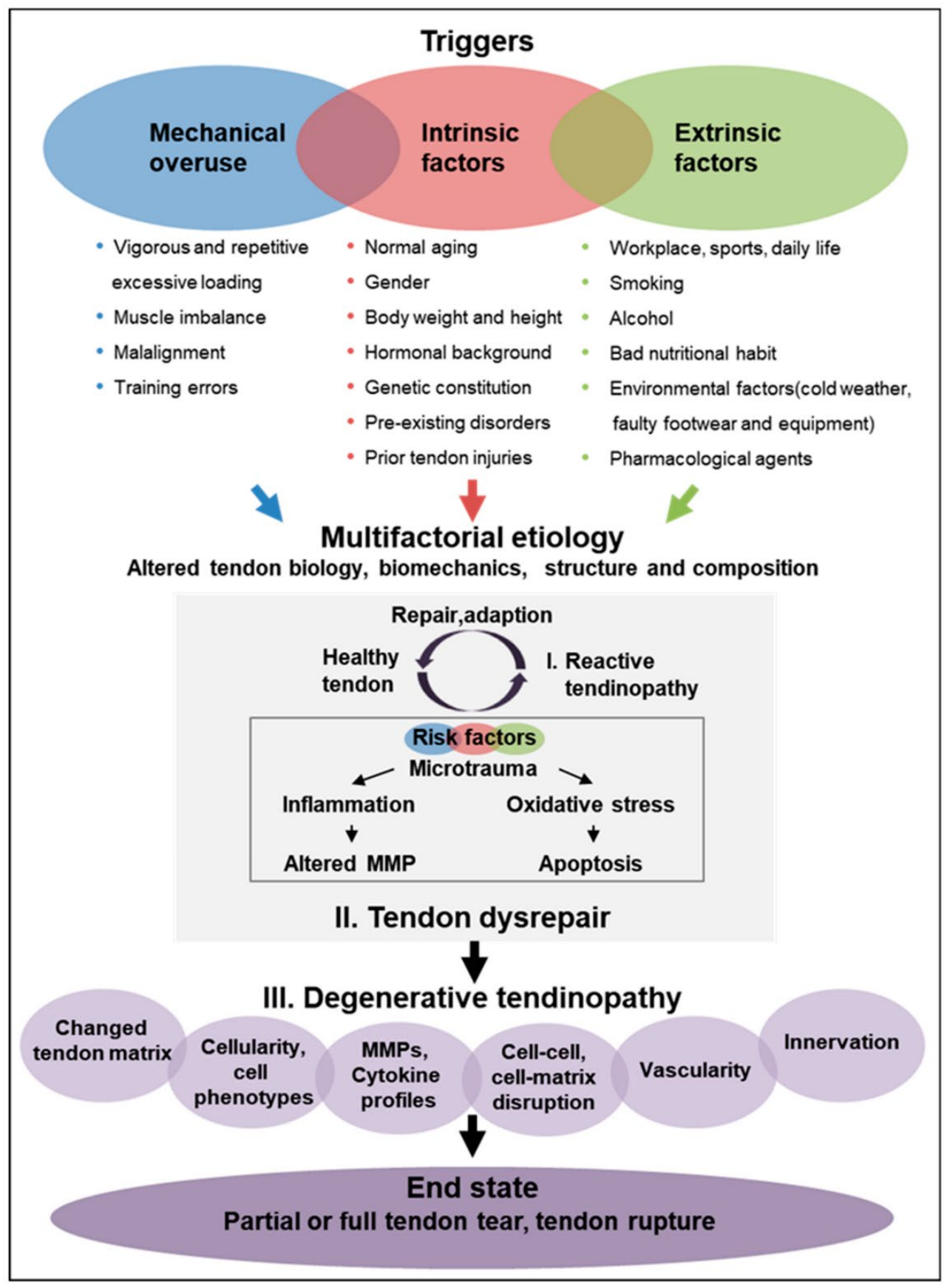




\section{Resistance training in tendinopathy}

\subsection{Resistance training Protocols}

Although Stanish et al. [87] was the first to publish on the concept of resistance training as a treatment for tendinopathy, with a predominately eccentric based protocol, eccentric training was popularised by the Alfredson eccentric heel-drop protocol for Achilles tendinopathy published in 1998 [88]. Since then eccentric resistance training has become the dominant conservative intervention strategy for lower limb tendinopathies over the last two decades [89]. There are however some important differences between these protocols, with Stanish recommending that patients perform the eccentric exercises with no pain, while Alfredson recommended pushing through pain [90]. The Alfredson protocol has also been modified for patellar tendinopathy in several studies, in the form of an eccentric decline squat protocol [91-92]. Although eccentric training has positive effects in treating tendinopathies, there are several issues related to eccentric biased training protocols. There is currently no strong evidence to suggest that decreasing or eliminating concentric actions from the stretch-shortening cycle is appropriate when treating chronic tendinopathies [93]. However, eccentric only training has shown better results when compared with concentric only, for Achilles [94], patellar [95] and tennis elbow tendinopathies [96].

Systematic reviews have evaluated the evidence for eccentric resistance training, concluding that high-quality evidence is lacking despite positive clinical outcomes in lower limb tendinopathies [97-99]. Despite Alfredson's initial high success rate with an athletic cohort, it is apparent from the evidence that not all patients have positive clinical outcomes from isolated eccentric training. Sayana et al. [90] found that $45 \%$ of patients were considered to have failed treatment with eccentric training based on pain and function outcomes, indicating that it may not be suitable for all patients. However, other single and combined contraction types of resistance training have been investigated, including concentric-eccentric, isolated concentric, and combined plyometric training [100]. 
More recently, Heavy Slow Resistance Training (HSRT) with heavy-load concentric-eccentric contractions, has become more widespread in research and clinical practice [89]. This method was first successfully implemented in patellar tendinopathy [101] and later investigated with positive outcomes in Achilles tendinopathy [102] and Plantar heel pain (PHP) [103] based on the same loading principles and volume progression. Whereas the Alfredson eccentric protocol stipulates a strict protocol of 180 repetitions daily, HSRT adheres more to scientific training principles, such as progressive increases in load and volume and increased rest periods (Table 1 ). Recent evidence suggests that HSRT may have superior clinical outcomes compared to isolated eccentric training interventions and leads to greater patient satisfaction in treating lower limb tendinopathies [101-103]. Despite this, evidence suggests that even HSRT protocols do not reach intended dosage levels and may require better loading and progression methods and a more individualised approach rather than a standardised protocol [26].

The high forces and loads produced during slowly performed concentric and eccentric contractions may stimulate tendon remodelling and compliance by stimulating collagen synthesis and reducing neovascularization when applied progressively [104]. Through the process of mechano-transduction, exercise can influence cell homeostasis and may stimulate tendon regeneration [105]. However, recent evidence suggests that clinical improvement from exercise loading interventions may be due to improved tendon mechanical properties, rather than altered tendon structure [106]. Resistance training has also been shown to be more effective than stretching for improving flexibility, reducing injury risk inducing length changes in short muscles via sarcomerogenesis [107-112]. 
Table 1: Evidence-based resistance training protocols in lower limb tendinopathy

\begin{tabular}{|c|c|c|c|c|c|c|c|}
\hline Protocol & Tendinopathy & $\begin{array}{l}\text { Exercise } \\
\text { type }\end{array}$ & $\begin{array}{l}\text { Sets, } \\
\text { repetitions }\end{array}$ & frequency & Duration & Progression & Pain \\
\hline $\begin{array}{l}\text { Stanish and } \\
\text { Curwin }\end{array}$ & Achilles & $\begin{array}{l}\text { Eccentric- } \\
\text { concentric, } \\
\text { power }\end{array}$ & $3,10-20$ & Daily & $\begin{array}{l}12 \\
\text { weeks }\end{array}$ & $\begin{array}{l}\text { Speed then } \\
\text { load }\end{array}$ & $\begin{array}{l}\text { Enough } \\
\text { load to be } \\
\text { painful in } \\
3^{\text {rd }} \text { set }\end{array}$ \\
\hline Alfredson & Achilles & Eccentric & 3,15 & $2 x$ daily & $\begin{array}{l}12 \\
\text { weeks }\end{array}$ & $\begin{array}{l}\text { Increase } \\
\text { load as able } \\
\text { (backpack) }\end{array}$ & $\begin{array}{l}\text { Enough } \\
\text { load to } \\
\text { achieve } \\
\text { moderate } \\
\text { pain }\end{array}$ \\
\hline Silbernagel & Achilles & $\begin{array}{l}\text { Eccentric- } \\
\text { concentric, } \\
\text { balance, } \\
\text { plyometric }\end{array}$ & Various & Daily & $\begin{array}{l}12 \\
\text { weeks }\end{array}$ & $\begin{array}{l}\text { Volume, } \\
\text { type of } \\
\text { exercise }\end{array}$ & $\begin{array}{l}\text { Acceptable } \\
\text { within } \\
\text { defined } \\
\text { limits }\end{array}$ \\
\hline Beyer & Achilles & $\begin{array}{l}\text { Eccentric- } \\
\text { Concentric } \\
\text { (HSRT) }\end{array}$ & $3-4,15-6$ & $3 \times$ week & $\begin{array}{l}12 \\
\text { weeks }\end{array}$ & $\begin{array}{l}\text { 15-6RM, } \\
\text { increase } \\
\text { load as able } \\
\text { (external } \\
\text { weight } \\
\text { machine) }\end{array}$ & $\begin{array}{l}\text { Acceptable } \\
\text { if not worse } \\
\text { after } \\
\text { exercise }\end{array}$ \\
\hline Rathleff & Plantar heel & $\begin{array}{l}\text { Eccentric- } \\
\text { Concentric } \\
\text { (HSRT) }\end{array}$ & $3-5,12-8$ & $3 \times$ week & $\begin{array}{l}12 \\
\text { weeks }\end{array}$ & $\begin{array}{l}\text { 12-8RM, } \\
\text { Increase } \\
\text { load as able } \\
\text { (backpack) }\end{array}$ & $\begin{array}{l}\text { Acceptable } \\
\text { if not worse } \\
\text { after } \\
\text { exercise }\end{array}$ \\
\hline Kongsgaard & Patellar & $\begin{array}{l}\text { Eccentric- } \\
\text { Concentric } \\
\text { (HSRT) }\end{array}$ & $4,15-6$ & $3 \times$ week & $\begin{array}{l}12 \\
\text { weeks }\end{array}$ & $\begin{array}{l}\text { 15-6RM, } \\
\text { Increase } \\
\text { load as able } \\
\text { (external } \\
\text { weight } \\
\text { machine) }\end{array}$ & $\begin{array}{l}\text { Acceptable } \\
\text { if not worse } \\
\text { after } \\
\text { exercise }\end{array}$ \\
\hline
\end{tabular}

RM: repetition maximum; HSRT: Heavy slow resistance training

\subsection{Loading issues}

There are more questions remaining than answers concerning the appropriate dosage of exercise for tendinopathy, which requires further invesigation on the optimal dosage and methods to better individualise the exercise treatment protocols. There is a tendency with lower limb tendinopathy, to quickly dismiss exercise as treatment if a patient does not quickly respond to the one-size-fits-all exercise program, and instead pursue other more costly and invasive treatment 
options [73]. To suitably address the needs of the individual, load prescription and dosage needs to be patient specific to ensure that it is adequate and appropriate. The staging of tendinopathy and subsequent implications on exercise selection is another area that requires individual consideration [113]. At present, there is insufficient evidence to define the exact speed, intensity and duration of resistance training needed nor predict, for certain, the longterm effects of resistance training for lower limb tendinopathy. It is relatively common for patients with Achilles tendinopathy to fail to respond to conservative treatment. For example, in an eight year study of 83 patients with chronic Achilles tendinopathy, 29 percent failed conservative management and required surgical intervention [114]. Individualisation of training progression is also required with selection of appropriate loads for the individual patient required to attenuate for their sport and performance level. Individual progression of resistance training to plyometric exercises is needed, to effectively progress athletes to return-to-sport training volume and intensity [115].

The overload principle speaks to the necessity to stress biological tissues beyond their current thresholds to increase tolerance to subsecjuent stresses and avoid future injuries. Greater load tolerance can be achieved by training at higher loads, which also has positive effects on remodeling of the degenerated tendon [116]. However, the Alfredson protocol for example involves training twice daily for 12 weeks, meaning it is unlikely high loads are being achieved. It is reccommended that no more than 3 high-intensity training sessions should be undertaken within a week in the recovering tendon, to allow adequate recovery and collagen synthesis $[10,115]$. Adequate rest periods are required in training protocols for tendon adaptation in relation to anabolic and catabolic processes involved in tendon remodelling [117]. Resistance training for longer than 12-weeks may also be necessary, in order to gain sufficient adaptation and positive results for lower limb tendinopathies [118]. It is belived that the exercise load has to be relatively high in order to stimulate tendon remodelling, which can explain why forced eccentric toe-raises, giving high loads, also give better results than using regular concentric/eccentric toe-raises. There is, however, no direct research showing that high eccentric loading is the best option for lower limb tendinopathies [119]. The dosage (e.g., number of repetitions, days per week and duration of a contraction) 
and type of exercise are important characteristics of an exercise program, with loads as high as $80 \%$ of 1 repetition maximum (RM) having been used for isometric (80\% 1RM) and isotonic exercises (80\% 8RM) [120]. Beneficial effects from rehabilitation for tendons require high load per repetition. Furthermore, a high percentage of RM in leg extension exercises has been shown to improve muscle strength and neural activation. However the precise mechanism of effect, optimal dosage and loading strategy has not yet been determined and further research is required [120].

Several studies have advocated the need for higher tendon loading during lower limb tendinopathy rehabilitation programs, with the type of load even being considered inconsequential [121]. The Alfredson protocol is the most commonly used protcol and consists of up to 180 repetitions daily, with additional weight added via a backpack in most studies. However, performing an eccentric exercise with a backpack in excess of $20 \mathrm{Kg}$ requires significant therapist involvement and may be one reason most studies only use bodyweight with high repetitions [121]. Another issues is that patients often do not accurately record their daily logs or falsely declare a good adherence to training programs. It is often postulated that active individuals have a better compliance for the prescribed exercises than nonactive individuals, and studies involving athletes have typically had higher succes rates from resistance training [88, 90, 122]. However in a study in an active population, more than a quarter of patients reported performing the exercises at an intensity reduced to less than half of what was prescribed [64]. Regardless of the intervention population, individualized exercise programs should be adequately supervised, reviewed, and progressed to ensure adherence and resolution of the tendinopathy [123]. The effectiveness of resistance training alone may increase with intensive care taking, such as having patients perform exercises with supervision four times per week for eight weeks as opposed to at home and unsupervised [124].

There is currently little consensus regarding which variables might influence the outcome of training, including whether training should be painful, home- versus clinic-based training, the speed of the exercise, training duration, and progression 
methods [125]. Large randomized controlled trials that consider these parameters and include blinded assessors and extended follow-up periods are warranted. Resistance training at a high intensity level of training, with gradual increases in loading, are required to create positive effects on both the muscle and tendon. Although the importance of mechanical loading through exercise in patients with tendinopathy is well established, the optimal exercise protocol contents and loading dosages require further investigation and may include aspects of motor control, proprioception, strength, malalignment, and flexibility [126]. The effects of different loading strategies need to be investigated in tendinopathy before they can be recommended in clinical practice, and findings in one type of tendinopathy may not necessarily be generalizable to others [127]. As previous research on lower limb tendinopathies has not found superiority of one specific resistance training type, the long-term effects of different loading programs in tendinopathy remain to be investigated [127].

As recognised by Purdam et al. [128] there is a question of whether most of the published studies are offering strength training, or may they be better described as active stretching with relative low intensity eccentric actions [19]. It seems that published works on eccentric protocols do not offer true strength training and it might be that only HSRT develops the minimum level of load and tension to identify them as strength training based on scientific training principles. Recent evidence suggests that an intensity threshold above $70 \%$ of maximum is required to cause adaptations in tendon properties, including mechanical, material and morphological tendon changes [129-130]. However, with the high repetition volume and inadequate loading in current protocols, it is unlikely this intensity is being achieved, which may be related to poor outcomes. Performing very slow repetitions (often 6-8 seconds) at a high repetition volume, may also lead to reduced intensity. Perhaps a better approach may be to perform less repetitions at a higher load with increased sets while maintaining the slow tempo implemented in HSRT, such as the approach known as 'cluster training' which could help maintain sufficient intensity and volume [131]. In conjunction with decreased repetitions and increased loading intensity, autoregulation or selfselection of within-session load may also account better for the principle of 
individualisation and allow for better individual outcomes, by tailoring the training load to an individual's response.

\subsection{Kinetic chain strength issues}

Strengthening of the entire kinetic chain, particularly the gluteal muscles in tendinopathy rehabilitation has been advocated considering its successful application to a plethora of musculoskeletal disorders with similar aetiologies [132-145]. Gluteal strengthening for loss of lumbopelvic control impairing motor control and the kinetic chain has been recommended in patellar and Achilles tendinopathy [146]. Recently, several studies have shown improvements in pain and function from targeted hip strengthening exercises in PHP [147-149]. Hip muscle weakness can cause excessive adduction and medial rotation of the hip causing dynamic knee valgus and overpronation [150-152]. Reduced strength of the hip abductors and rotators is identified as a risk factor for lower limb tendinopathy due to altered biomechanics [153-158]. Therefore, strengthening these muscles could improve dynamic lower limb alignment and reducing excessive strain on lower limb tissues [159-161]. Hip muscle activation can also impact on force production at the ankle joint, impacting gait which may contribute to lower limb pain [162-163].

Malliaras et al. [89] has suggested that an eccentric-concentric loading programme for individuals is more beneficial than eccentric only for lower limb Itendinopathy, particularly in those with concentric muscle weakness that may not recover with isolated eccentric training. Every patient presents individually, and this may necessitate a focus on kinetic-chain factors, that are not addressed with isolated eccentric training [164]. It is known that athletes with patellar tendinopathy can benefit from a more comprehensive rehabilitation program including an exercise program to improve muscle-tendon function and to normalize the kinetic chain [165]. To optimally manage tendinopathies, overall functional capacity should be assessed to facilitate progressive overload of the tendon itself and the kinetic chain [166]. Failure to adequately address isolated muscle deficits, kinetic-chain deficits, or biomechanics may lead to suboptimal 
rehabilitation in tendinopathy [115]. Therefore, it is essential to address each intrinsic and extrinsic causative risk factor individually during the rehabilitation period and make adaptations to the environment if necessary [167].

Lower limb tendinopathy rehabilitation should be based on progressive loading of the muscle-tendon unit and the whole lower extremity and kinetic chain. However, the optimal protocol of exercise loading needs further investigation [168]. For athletes, individual needs can be addressed through a comprehensive evaluation by the sports rehabilitation personnel to identify areas of special needs and shortcomings in the biomechanical chain [169]. The formulation of an individualised rehabilitation programme must take special consideration in that elite athletes require more intense rehabilitation than amateur athletes for successful return to sport and avoiding a relapse of the pathology due to the amplified training demands and level of participation [169]. It is always considered a necessity to address strength deficits in athletes with tendinopathy [77]. Patellar tendinopathy rehabilitation based on individualising the rehabilitation intervention according to the participant's specific biomechanical deficiencies and load tolerance has demonstrated improvement in pain and functionality in elite rugby union players with patellar tendinopathy [80].

The gluteus maximus muscle is considered to be an important hip extensor muscle to strengthen during lower limb tendinopathy rehabilitation [170]. Previous research has shown that lower limb tendinopathy is associated with weak hip extensor muscles and poor lumbopelvic control, which has the probability to modify the load distribution on the lower limb kinetic chain [171]. A recent delphi study of clinical practice found there was a strong predisposition (87\%) towards hip strengthening as a component of patellar tendinopathy rehabilitation programmes [80]. Similariy, a recent survery of Brazilian physical therapist practice for patellar tendinopathy, reported that hip strengthening exercises were second only to quarcipes eccentric training, in terms of frequency of prescription [172]. Rehabilitation interventions aiming to improve hip extensor muscle strength in patellar tendinopathy have shown positive outcomes. An 8-week intervention of hip muscle strengthening and jump-landing modification decreased 
pain and disability and improved jump-landing biomechanics in an athlete with patellar tendinopathy [170]. However, a variety of biomechanical risk factors, both local and distal to the knee joint, have been associated with the development of lower limb tendinopathy [173]. The clinician should keep these factors in mind while tailoring a comprehensive intervention for treating athletes with patellar tendinopathy. The clinical effectiveness of existing tendinopathy management options, including that of eccentric exercises, is not yet satisfactory. It is clear from the isolated eccentric-loading evidence that not all patients respond to this intervention, which highlights the importance of studies investigating the effects of alternative or additional exercise treatment options. Future research on resistance training interventions in tendinopathy should focus on addressing proximal, local, and distal factors including strengthening of the kinetic chain as opposed to isolated strengthening of the pathological tendon [170].

\subsection{Reactive strength issues}

Athletic activities such as running and jumping involve energy storage and release from tendons, supported by strong muscular contractions, known as the stretchshortening cycle (SSC) [174]. Plyometric exercise, which utilises the SSC, is a common training practice among athletes. It has been shown to improve maximal rate of torque development, maximal voluntary contraction, jump performance, running economy and leg stiffness in active people [175-177]. In athletes, lower limb tendinopathy occurs most commonly in those participating in activities involving the SSC, such as running and jumping [89]. During athletic activities, the Achilles tendon experiences loads six to twelve times bodyweight. These high loads require considerable strength and power to repeatedly generate force and enable the storage and release of energy during athletic activity [83]. Therefore, rehabilitation programs focusing solely on strength via the use of various heelraise programs, may lead to suboptimal functional capabilities, persistent strength deficits, inadequate rehabilitation and ultimately high recurrence rates of tendinopathy [178-179]. 
The lack of consensus in physiotherapy of what constitutes strength may be a factor in the predominance of unidimensional rehabilitation programs. Little consensus exists on the presence of strength deficits in tendinopathy, leading to the implementation of ineffective rehabilitation programs focusing on one type of exercise only in clinical practice [180]. To clarify this uncertainty, subcategories of strength have been proposed, including maximal strength, which involves maximal force development through high-load, low-velocity movements; explosive strength, which is the ability to rapidly produce muscle force through medium- to high-load, high-velocity movements (e.g. rate of force development); and reactive strength, which is the ability of the calf-muscle complex to store and release energy through sufficient function of the SSC through low-load, highvelocity exercises such as hopping and jumping [181]. Deficits in SSC power and efficiency have been found in those with Achilles tendinopathy, measured by reduction in maximal hop distance and leg stiffness during submaximal hopping [182-183]. After six months of recommended exercise rehabilitation in Achilles tendinopathy, not including plyometric exercise, persistent SSC impairments have been found after one year [52].

Heavy-slow resistance training in healthy individuals has been found to increase tendon stiffness, whereas plyometric training increases joint stiffness and jumping performance [176]. This suggests that plyometric exercise likely has complimentary effects to HSRT in tendinopathy rehabilitation and may reduce persistent SSC deficits which can decrease rehabilitation effectiveness. A consistent barrier to implementing plyometric exercise for lower limb tendinopathy in rehabilitation is that they are not implemented progressively and therefore aggravate symptoms $[146,184]$. The common belief that plyometric activities will negatively impact on tendinopathy rehabilitation is not supported by evidence and it may be beneficial for improving outcomes [180]. In those with Achilles tendinopathy who continued plyometric exercise such as sprinting, jumping and hopping, similar pain and function was reported to those who stopped all plyometric activities [126]. This study identified that SSC loads are tolerable during tendinopathy rehabilitation in active people, provided they are guided by a pain and symptom monitoring model [126]. Another study in Achilles tendinopathy, used a loading intervention integrating plyometric exercise for 12 
weeks to address the entire strength spectrum, which resulted in improvements in pain and disability at 12 months [52]. Further studies integrating plyometric training in tendinopathy with traditional HSRT are required, particularly in PHP as it has yet to be investigated [185].

A recent systematic review identified that individuals with Achilles tendinopathy demonstrate strength deficits across the strength spectrum for maximal, reactive and explosive strength compared to the uninjured side or asymptomatic controls [180]. This study concluded that the current focus on maximal strength in tendinopathy rehabilitation and the lack of emphasis on reactive or explosive strength may not optimally match the entire strength spectrum. The authors argued this could explain why Achilles tendinopathy rehabilitation is only moderately effective with recurrence as high as $27 \%$ and why SSC deficits persist post rehabilitation [186]. The similar lack of emphasis of plyometric training in PHP rehabilitation may also help explain why rehabilitation focused only on strengthening such as HSRT is only moderately effective [26]. Approximately $40 \%$ of PHP patients have pain and symptoms two years after diagnosis and treatment, suggesting new and effective treatments are warranted [103]. Training only one aspect of an individual's strength profile, which is common in lower limb tendinopathy rehabilitation with concentric-eccentric HSRT, will likely not optimally improve performance across the entire strength spectrum [187]. However only Silbernagel et al. [52] has addressed the entire strength spectrum in Achilles tendinopathy rehabilitation, with no studies currently addressing it with PHP [185]. Plyometric loading seems to be a more potent stimulus for muscle compared to tendon adaptation, so it may compliment HSRT programs which more potently stimulate tendon adaptation [188]. Increased tendon stress and strain due to a non-uniform musculotendinous development has been observed recently in adolescent volleyball athletes, a high-risk group for tendinopathy [189]. These findings highlight the importance to deepen the current understanding of the interaction of loading and maturation and suggests SSC training via plyometric exercise may act as a tendinopathy prevention strategy [180]. 
Recently, a pain-guided progressive hopping intervention was found to be safe and feasible when added to currently recommended HSRT exercise and education for AT in recreational runners [190]. This study also included kinetic chain isotonic strength exercises for the gluteus Medius and maximus as recent studies have shown that weakness and delayed onset of the gluteal muscles are common during running in those with lower limb tendinopathy [191]. Despite providing evidence that plyometric exercise may have complimentary effects to HSRT and improve rehabilitation outcomes, there is a dearth of studies investigating the effects of plyometric exercise in tendinopathy rehabilitation [180]. This is perhaps due to the perception by patients and clinicians that plyometric exercise is potentially damaging and counterproductive in tendinopathy rehabilitation [190]. However, providing education on the benefits of exercise for pain can reduce self-reported pain following acute exercise compared to those not receiving pain education [192]. The following sections provide an overview of the application of autoregulation within strength and conditioning, before finally considering the potential application of autoregulation in physiotherapy and its integration into current HSRT protocols in tendinopathy.

\section{Periodization in resistance training}

In the profession of Strength and Conditioning (S\&C), the use of periodized programming for training is generally accepted as a more effective way of ensuring strength gains for athletes compared to non-periodized programming [193]. Periodization can be defined as the planned distribution of training to increase the potential for achieving optimal sports performance at a predetermined time point [194-195]. Block periodisation has been shown to effectively improve strength and power in athletes and is based on several distinct training mesocycles; hypertrophic, basic strength and maximal strength [196-197]. The mesocycles are performed in order, with an increase in intensity and decrease in overall training volume throughout the model [198]. Maximal strength is considered one of the most important factors in maximising athletic performance and has been shown to improve performance in many running sports and reduce injury risk [199-201]. In physiotherapy, strength exercise is one of the most common treatment 
prescriptions for musculoskeletal disorders such as tendinopathy [202-203]. Although there has been research showing the applicability of using structured periodized training in the rehabilitation of athletes, there is a lack of studies on its use on athletes with tendinopathy or the general population in physiotherapy [204-208].

Periodized strength training typically manipulates intensity as a percentage of $1 R M$, which is obtained prior to beginning training. This approach does not account for daily fluctuations in training performance due to fatigue and strength levels which may affect its accuracy and outcome. There can be significant variations in daily strength as high as $20 \%$, resulting in variable performance when using a fixed method [205]. Individual variability in factors such as genetics, sleep, nutrition, psychological stress, lifestyle factors, total training load and heart-rate variability may also affect training performance [209-210]. Fixed periodization also does not account for individual training response and as such the potential for strength gains may be greater than this model facilitates [211-212]. Personalized exercise prescription and progression may be a more appropriate method which better accounts for the large inter-individual and biological variability that exist in response to training interventions [28]. Therefore, using a method known as autoregulation within training programs would allow individuals to increase strength at their own capability and can allow constant adjustment of repetitions which may prevent plateaus in training [28].

\section{Autoregulation}

Autoregulation is a form of periodization which involves adjusting the variables of strength training based on an individual's daily or weekly readiness to train [28]. Due to the multifactorial nature and wide variances in individual responses to training, implementing autoregulated training may lead to improved training adaptations compared to fixed training models [213-214]. Although autoregulation originated in physiotherapy research and is a common practice in S\&C there is a lack of current research on its effectiveness. The principle of individualization is an essential consideration when designing resistance training 
program to optimize adaptations to training [215-216]. Studies have shown that when training is tailored to the individual, training adaptations are enhanced [217]. Despite a paucity of interventional studies on autoregulation, several studies have utilised autoregulation training via the progressive resistance exercise (PRE) model. The PRE model originated in rehabilitation research and involved progressively heavier sets of ten repetitions: 1 set at $50 \%$ of $10 \mathrm{RM}, 1$ set at $75 \% 10 \mathrm{RM}$ and 1 set at $100 \% 10 \mathrm{RM}$ [218].

A daily adjustable progressive resistance exercise (DAPRE) program was implemented with an autoregulated set which accounted for daily responses in a patient's rehabilitation [219]. This approach allowed for an interactive protocol which objectively determined the optimal time to increase resistance and the optimal amount of weight during exercise. This provided more efficient rehabilitation accounting for individualised reacquisition of strength [220]. A specific autoregulatory program derived from the DAPRE method, expanded on this concept in order to meet different training goals of hypertrophy and strength/power, and allow for continual body adaptation through the specific adaptation to imposed demand (SAID) principle [221-222]. This method, termed Autoregulatory Progressive Resistance Exercise (APRE), enhances the previous DAPRE method by introducing training cycles aimed at improving hypertrophy, strength and power regimes of conditioning. This allows for continual neuromuscular adaptation by systematically changing program variables thus promoting efficient performance gains [223]. The autoregulation approach may help facilitate rapid strength gains without the risk of excessively overloading the joints and tissues, potentially causing injury [224-225]. Without monitoring and adaptation, the most elegant program can quickly become irrelevant. Furthermore, the physiotherapist has the added challenge of dealing with the healing process. While adherence to a consistent approach will drive adaptation, structured variability is also necessary within this framework to ensure relevance on any given day. Therefore, modifiable programming based on relevant feedback is important, which can be achieved with autoregulation [226]. 
Mann et al. [28] adopted an APRE model of periodization and applied it with collegiate athletes. There was a set number of repetitions performed at a percentage of $10 \mathrm{RM}, 6 \mathrm{RM}$ and $3 \mathrm{RM}$, with athletes self-adjusting the weight after the third set. Athletes performed a maximum number of repetitions to failure during the third set with $100 \%$ of their 6RM, with the number of repetitions completed determining the load for the fourth set. This autoregulation method was not only daily adjusted but also decided weekly changes in load, however volume and intensity were not controlled due to the inclusion of sets with as many repetitions as possible. These individual differences in volume and intensity could be a reason why autoregulation training is effective [221]. This autoregulation method proved effective in increasing maximal bench press and squat strength over six weeks in athletes compared to traditional linear periodization [28]. This autoregulation approach was a modification of the DAPRE system that allows for a more flexible application than more traditional approaches [227]. Tables two and three highlight the APRE training routines and the amount of load adjustment following the third set of repetitions to failure.

Another study found that autoregulation training significantly increased leg press strength compared to non-linear periodization in novice weightlifters over 12 weeks [228]. The autoregulation group were able to choose between three training sessions of various intensity depending on their energy and motivation levels (10RM, 15RM, or 20RM, repetitions of free weight exercises). Unlike the previous study [28], volume and intensity were matched between groups, therefore the autoregulation group had a limited number of exercise selection. Although the autoregulation group performed better in leg press strength, both groups significantly improved, which may have been attributed to all participants being new to strength training. Therefore, rapid improvement in strength due to improved neuromuscular efficiency and motor unit recruitment would be expected [229]. However, improvements in chest press strength were not significantly different between the two groups.

In a physiotherapy case report by Ardali [230] a DAPRE protocol was implemented alongside standard rehabilitation to maximize quadriceps muscle strength in a 61- 
year-old female following total knee replacement. In phase I, the patient received three visits with emphasis on oedema management, improving left knee range of motion, and reducing pain. Phase II consisted of two main components: (1) a DAPRE protocol aimed at maximizing the quadriceps strength and (2) functional training aimed at improving normal gait patterns, transfers, and dynamic balance. The patient made substantial improvements in both quadriceps muscle strength and functional performance in the first seven weeks following surgery. The patient had a pain free return to daily living activities. The results suggest that early initiation of a DAPRE protocol was free of adverse events and helped improve quadriceps strength and functional performance for this patient [230].

In another physiotherapy case report by Horschig et al. [223], an APRE model of periodization was investigated using the back squat during the rehabilitation of a 17-year-old male athlete recovering from $A C L$ reconstruction. A secondary aim was to examine the applicability of this method in the transitional period from rehabilitation to strength and conditioning for which a current disconnect exists. Starting at 20 weeks post-operatively, the athlete was able to show a 10 pounds daily average increase with the $10 \mathrm{RM}$ protocol, a 6 pounds daily average increase during the 6RM protocol, and a 6.3 pounds average increase with the 3RM protocol. A 2 RM of 390lbs was performed in the back squat at the conclusion of the program at 39 weeks post-operatively. The results strengthen the current limited knowledge regarding periodization during the later phases of rehabilitation and the transition back to sport participation time period, while at the same time providing new insights for future protocol considerations in rehabilitating athletes. The APRE method of periodization provides an individualized progressive resistive protocol that can be used to safely and effectively increase strength in both healthy populations and individuals recovering from injury during short-term training cycles. Although autoregulation research originated in rehabilitation and these two case reports provide encouraging results, there is a clear lack of longitudinal and interventional research of its effectiveness in physiotherapy. 
Table 2: Adjusted progressive resistance exercise training routines

\begin{tabular}{|c|c|c|c|}
\hline Set & 3RM Routine & 6RM Routine & 10 RM Routine \\
\hline 0 & Warm-up & Warm-up & Warm-up \\
\hline 1 & $\begin{array}{l}6 \text { repititions ( } 50 \% \text { of } \\
\text { 3RM) }\end{array}$ & $\begin{array}{l}10 \text { repititions ( } 50 \% \text { of } \\
6 \mathrm{RM})\end{array}$ & $\begin{array}{l}12 \text { repititions } \\
\text { ( } 50 \% \text { of } 10 \mathrm{RM})\end{array}$ \\
\hline 2 & $\begin{array}{l}3 \text { repititions }(75 \% \text { of } \\
\text { 3RM) }\end{array}$ & $\begin{array}{l}6 \text { repititions ( } 75 \% \text { of } \\
6 \text { RM) }\end{array}$ & $\begin{array}{l}10 \text { repetitions } \\
\text { ( } 75 \% \text { of } 10 \mathrm{RM})\end{array}$ \\
\hline 3 & $\begin{array}{l}\text { Repititions s to failure } \\
\text { (3RM) }\end{array}$ & $\begin{array}{l}\text { Repititions to failure } \\
(6 \mathrm{RM})\end{array}$ & $\begin{array}{l}\text { Repititions to } \\
\text { failure (10RM) }\end{array}$ \\
\hline 4 & $\begin{array}{l}\text { Adjusted Repititions } \\
\text { to failure* }\end{array}$ & $\begin{array}{l}\text { Adjusted Repititions } \\
\text { to failure* }\end{array}$ & $\begin{array}{l}\text { Adjusted } \\
\text { Repititions to } \\
\text { failure* }\end{array}$ \\
\hline
\end{tabular}

*Denotes training load must be adjusted according to table 2

RM: repetition maximum

Table 3: Example adjustments for APRE protocols

\begin{tabular}{|c|c|c|c|c|c|}
\hline \multicolumn{2}{|c|}{ Adjustments for 3RM } & \multicolumn{2}{|c|}{ Adjustments for 6RM } & \multicolumn{2}{|c|}{ Adjustments for $10 \mathrm{RM}$} \\
\hline Repetitions & Set 4 & Repetitions & Set 4 & Repetitions & Set 4 \\
\hline $1-2$ & $\begin{array}{l}\text { Decrease } \\
5-10 \\
\text { pounds }\end{array}$ & $0-2$ & $\begin{array}{l}\text { Decrease } \\
5-10 \\
\text { pounds }\end{array}$ & $4-6$ & $\begin{array}{l}\text { Decrease } \\
5-10 \\
\text { pounds }\end{array}$ \\
\hline $3-4$ & Same & $3-4$ & $\begin{array}{l}\text { Decrease } \\
0-5 \text { pounds }\end{array}$ & $7-8$ & $\begin{array}{l}\text { Decrease } \\
0-5 \text { pounds }\end{array}$ \\
\hline $5-6$ & $\begin{array}{l}\text { Increase } 5 \text { - } \\
10 \text { pounds }\end{array}$ & $5-7$ & Same & $9-11$ & Same \\
\hline \multirow[t]{2}{*}{$7+$} & $\begin{array}{l}\text { Increase } \\
10-15 \\
\text { pounds }\end{array}$ & $8-12$ & $\begin{array}{l}\text { Increase 5- } \\
10 \text { pounds }\end{array}$ & $12-16$ & $\begin{array}{l}\text { Increase } 5- \\
10 \text { pounds }\end{array}$ \\
\hline & & $13+$ & $\begin{array}{l}\text { Increase } \\
10-15 \\
\text { pounds }\end{array}$ & $17+$ & $\begin{array}{l}\text { Increase } \\
10-15 \\
\text { pounds }\end{array}$ \\
\hline
\end{tabular}

RM: repetition maximum 
Autoregulation training should not be considered a stand-alone periodization model and it can be applied individually within periodization in three ways; to adjust load within training, to progress weekly load or to select daily load prior to training $[213,231]$. The modification of training volume with autoregulation has typically been the training variable successfully adopted in studies, however other training variables have also been examined. The effectiveness of autoregulation of rest intervals in trained men compared to fixed rest intervals has been successfully demonstrated, resulting in greater performance outcomes [232]. A recent systematic review also concluded that autoregulated rest periods were as good or better than structured ones for strength and muscle gain [233].

\section{Autoregulation Progression Methods}

\subsection{Rating of perceived exertion}

The rating of perceived exertion (RPE) scale has been found to be a reliable measure of not only training session intensity, but also specific exercise intensity within a session [234-235]. Although most studies have found RPE an accurate measure of fatigue during strength training, some have found it not to be [236239]. However, the more experienced in training someone is, the more accurate an RPE scale becomes, with it being less accurate for younger or novice athletes [240-241]. Within physiotherapy, an RPE scale offers advantages as it allows intensity monitoring without establishing 1RM, which may be contraindicated due to injury [226]. However other models exist to estimate 1RM without lifting a true 1RM such as the Oddvar Holten Curve and other models which are used to establish an estimated 1RM based on submaximal loads taken to failure [208, 242]. Recommendations have been published for using the Borg RPE scale with resistance band strength training in physiotherapy [236, 243]. A recent study in patellofemoral pain patients adopted this model with an RPE greater than 6 considered desirable [244]. Although this model may be useful with general population patients only using resistance bands, exercise rehabilitation programs in athletes with tendinopathy typically require using much heavier external loads to derive the adaptations required. This suggests that more specific progression 
models for heavier resistance training in rehabilitation may be necessary to achieve optimal progression.

\subsection{Repetitions in reserve}

The Reactive Training Manual by Tuchscherer [245] details an autoregulation training method common in powerlifting based on an RPE scale. The scale allows an individual to evaluate their performance based on the number of repetitions they perceive they could have completed prior to muscular failure. The scale goes from 1-10, with 10 being the maximum number of repetitions. This model is like a repetitions in reserve (RIR) model and is considered by some authors to be more appropriate for resistance training than common RPE methods used in endurance training [246]. An RPE of eight would indicate two extra repetitions could be completed for example, guiding adjustments in training load. This type of RIRbased RPE scale may have more specificity than the traditional Borg scale RPE, which has shown submaximal scores, even when individuals perform exercises to muscular failure [247-249]. Therefore, within S\&C it has been suggested this specific RPE is more accurate and superior for assessing intensity compare to traditional RPE during resistance training [250-252].

Recently, a resistance training specific RPE scale has been demonstrated to be effective for measuring effort during a training session and subsequently adjusting load [246]. Like the previous model [245] it measures RIR, where the individual records an RPE during or after completing a set, with 10 being the maximum, 10RPE $=$ ORIR. The model allows an individual to estimate the amount of additional repetitions remaining at a given load. Consequently, if an achieved RPE is too low or high, training load can be altered accordingly and objectively [246]. For example, an RPE of 9 or 10 could require a load reduction of $2.5-5 \mathrm{~kg}$, respectively. This method may be preferable for load assignment to APRE models as they involve training to failure at pre-determined loads, meaning a lack of flexibility in training loads and exertion, whereas the RIR RPE model avoids training to failure [246]. For example, in APRE studies, athletes perform a maximum number of 
repetitions to failure during the third set with $100 \%$ of their 6RM, with the number of repetitions completed determining the load for the fourth set [28]. Although this resistance training specific scale has been validated in experienced and novice weightlifters, its application in rehabilitation such as musculoskeletal physiotherapy has not been evaluated [246]. Nevertheless, this training specific RIR-based RPE scale is a potential method to regulate training load in clinical patients prescribed resistance training, such as those undertaking traditional resistance loading programs in tendinopathy [253]. Recently, the specific RIR based RPE model was compared against a traditional 1RM load assignment in resistance trained males. Although both loading types were effective, the RPE strategy provided a small 1RM strength advantage in most participants [30]. Another study compared the RIR autoregulation approach with a fixed loading intervention based on 1RM for squat strength in trained men over 12 weeks. Although both groups improved squat performance, the RIR autoregulation group showed significantly greater improvements and trained at an overall higher intensity [254]. The results from these studies suggest that RIR as a method of autoregulation training can lead to superior strength gains in athletes compared to traditional fixed approaches. However, as a subjective method, it may be less effective than objective methods of autoregulation [255].

\subsection{Velocity based training}

An objective method of monitoring within training sessions is velocity-based training (VBT), which has become increasing popular due to new technology for monitoring repetition velocity [256]. Despite a lack of research on VBT, several models have been developed that determine intensity based on barbell velocity during lifting and the end of the set based on a predetermined velocity decrease [257-258]. Technological devices are available to allow quantitative visualisation of an individual's effort, by recording repetition velocity [259]. Research and practical application of VBT is becoming increasingly popular in S\&C and when VBT is applied systematically it allows for immediate feedback, fatigue control, monitoring of biomechanical changes and can guide the training process [260266]. However, for accurate measurements, individuals must perform fast 
concentric actions with good technique, training adherence and motivation, which may be a barrier for use in rehabilitation [267]. Recently, a VBT intervention was found to increase maximal strength and jump height in trained men compared with a traditional 1RM percentage-based training approach over six weeks [268]. The VBT group achieved these better outcomes while also having a reduction in total training volume compared with the traditional group, indicating a potentially more efficient training method. Despite the dearth of VBT research in physiotherapy, VBT may have a role within musculoskeletal rehabilitation, particularly with athletes who are involved in S\&C or transitioning from rehabilitation into S\&C [226].

\section{Autoregulation in physiotherapy}

\subsection{Self-management in physiotherapy}

Recent United Kingdom (UK) government policy has emphasised improving outcomes within the National Health Service (NHS) by placing the patient at the centre of all decisions taken about them. However, the NHS is also facing financial challenges and the need to deliver gains in efficiency (NHS 2011). Selfmanagement in physiotherapy has been suggested as a solution to these issues, by reducing the demand for regular contact with physiotherapists. Selfmanagement also offers opportunities to individualise care and there is evidence to suggest that an approach where patients are encouraged to take responsibility for their own care is no less effective than treatment requiring regular clinic attendance [269]. Self-management refers to situations where people are encouraged to actively manage their symptoms, treatment, consequences and life-style changes associated with their condition [270]. This process is facilitated through a therapeutic alliance, or partnership, between patient and physiotherapist. The self-managed framework consists of components currently regarded as effective mechanisms by which to enhance self-efficacy and facilitate self-management including: knowledge translation, exercise/ skill acquisition, self-monitoring, goal setting, problem solving and pro-active follow-up [271]. 


\subsection{Real-time feedback}

Evidence suggests that adherence to prescribed self-management exercise in physiotherapy patients can be improved by using interventions such as activity monitoring and feedback systems [272]. Whereas in S\&C, feedback methods such as VBT aim to help individuals maintain high exercise velocity, in physiotherapy, exercise is often performed too fast in musculoskeletal rehabilitation [273]. This results in contraction time being too short and too few repetitions, which can impede recovery due to low exercise dose [274]. As well as the overall load, factors such as adequate contraction time or 'time under tension' can influence adaptations such as increasing muscle protein synthesis [275]. Studies have found that both patients and healthy individuals often do not perform exercises in predefined contraction time, which affects exercise compliance and outcomes [276]. This could be particularly important during tendinopathy rehabilitation, where HSRT exercises are performed very slowly to maximise contraction time [26]. For example, a common HSRT program requires 8 seconds (3 seconds concentric, 2 seconds isometric, 3 seconds eccentric) to complete one repetition [103].

A new technology that can provide real-time feedback on exercises performed with an elastic band is a sensor called BandCizer (BandCizer Aps, Denmark). It has been validated to quantify contraction time, the number of repetitions performed, and the force used to stretch the band by measuring its thickness [273]. Data from the sensor can be transmitted to an iPad (Apple Inc, Cupertino, CA), with the BandCizer app providing real-time exercise feedback [278]. It has been found feasible for measuring contraction time and exercise dose during musculoskeletal physiotherapy [277]. Recently, the first RCT investigating BandCizer in musculoskeletal physiotherapy, found that real-time feedback on contraction time resulted in exercises being performed closer to the prescribed dose and induced larger strength gains than the control group [279]. Although this study was performed in those with patellofemoral pain, the prescribed contraction time was 8 seconds, the same time as repetitions in the PHP HSRT program. This suggests providing similar feedback may be applicable if applied in 
tendinopathy rehabilitation to improve compliance and adequate loading, which has been identified as a barrier to achieving desired outcomes [26].

\subsection{Pain-monitoring models}

The Common-sense Model of self-regulation of health and illness suggests that patients interpreting their pain response in a way that facilitates the use of exercise as a management strategy is pivotal [280]. Persistent beliefs that the pain is a sign of tissue damage and that rest is required to enable the tissue to recover can prevent rehabilitation being implemented successfully [281]. Such an appraisal would result in avoidance behaviour and prevent any level of engagement [282]. In this situation, reliance is placed upon the development of a therapeutic alliance where doubts and concerns can be expressed by the patient and reassurance offered by the physiotherapist along with an acceptable explanation of the cause of the problem [283]. Self-monitoring and appropriate interpretation of physiological signs is regarded as a cornerstone of successful self-management [284].

Several studies in tendinopathy have encouraged patients to monitor their pain response whilst exercising, which is recorded in a self-report diary, in the knowledge that pain should be produced whilst exercising but should be no worse upon cessation $[95,285-286]$. When the pain response abates this is suggested as the stimulus to progress the loaded exercise. In contrast to others who have used a numeric pain rating scale, such as pain no greater than $5 / 10$, to guide exercise progression, the self-monitoring intervention described enables the patient to judge what is manageable in terms of symptom response [287]. This decision reflects individual perceptions of what constitutes acceptability in terms of pain, which differs between individuals [283]. The SELF study by Littlewood et al. [286] was an RCT which aimed to evaluate the clinical effectiveness of a selfmanaged single exercise programme, which was self-progressed using painmonitoring versus usual physiotherapy treatment for rotator cuff tendinopathy. At six and twelve-months follow-up there was no significant difference between the 
groups. This study suggested no superiority of one intervention over the other in the short, mid or long-term and that a self-management programme based around a single self-progressed exercise via pain-monitoring appears comparable to usual physiotherapy treatment [286].

Progression via pain-monitoring in Achilles tendinopathy has also been found feasible. In those with Achilles tendinopathy who continued plyometric exercise such as sprinting, jumping and hopping, reported similar pain and function to those who stopped all plyometric activities [126]. This study identified that plyometric loads are tolerable during tendinopathy rehabilitation in active people, provided they are guided by a pain and symptom monitoring model [126]. Recently this model was expanded further in a feasibility cohort study. A painguided progressive plyometric hopping intervention was found to be safe and feasible when added to currently recommended HSRT exercise and education for Achilles tendinopathy in recreational runners [190]. Recreational and elite athletes with tendinopathy will need to adapt their training and rehabilitation parameters such as frequency, intensity and duration due to persistent pain. This could have significant consequences for athletes as it can restrain them from training for long periods, decreasing fitness levels and performance [288]. However, there have been a lack of studies investigated solutions to this problem, despite the high prevalence of tendinopathy in athletes [289]. The use of pain-monitoring models during rehabilitation may be a possible solution, to ensure adequate training levels are maintained.

Historically, rest from pain-provoking activities such as running, and jumping have been recommended as initial treatment in tendinopathy [114]. However, recommendations in the literature are vague when recommending some type of modified rest in which the pain-provoking activity should be limited or avoided [290-291]. As athletes are generally very physically active people, an over-long period of rest or decrease in physical activity due to tendinopathy may have a negative effect on their quality of life and sporting performance [288]. In tendinopathy research it is now generally accepted that a complete rest period is 
not helpful, with loaded exercise required for the healing process and continuing moderately pain-provoking activity may be beneficial when adjusted appropriately $[126,292]$.

\subsection{Autoregulation in tendinopathy}

Since the initial research in autoregulation, which was conducted with physiotherapy patients, there has been a lack of further research, particularly longitudinal research, with only case reports appearing in the physiotherapy literature [223, 230]. Despite the preponderance of research showing effectiveness of resistance training for musculoskeletal disorders, it is usually prescribed or investigated using pre-determined protocols [293]. Although the importance of identifying methods for enabling patient self-management with exercise is becoming increasingly emphasised in physiotherapy, using autoregulation methods for progressing self-managed exercise has been given little attention [272]. A common issue with pre-determined exercise programs in physiotherapy, is that prescription and progression of loaded sets and repetitions are often poorly defined and underdosed (Riel et al. 2019). If the dosage of training loads is not enough, then the mechanobiological stimulus may not be adequate to stimulate healing, resulting in poor outcomes (Khan and Scott 2009). Previous studies have shown an association between increased exercise dose and recovery for musculoskeletal disorders [274]. An option for increasing training dosage would be to prescribe a larger exercise dose, however compliance with exercise can be compromised by low self-efficacy [294]. An alternative approach to increase exercise dosage is to increase patient self-efficacy by empowering patients to be in control of their own rehabilitation [295]. To the authors knowledge, only two RCTs have investigated autoregulatory resistance training protocols versus standardised protocols in tendinopathy. One study in Achilles tendinopathy [296] and one in PHP [26] compared a self-dosed protocol with the conventional standardised heel-raise protocols based on the work of Alfredson and Rathleff respectively. Although these studies did not use any true autoregulation methods or distinct load progression, they are still innovative as they allowed the 
experimental group to self-select the amount of exercise completed as opposed to following a non-flexible protocol.

Riel et al. [26] recently investigated this approach in PHP patients by comparing a 12-week self-dosed HSRT program with a pre-determined program. The HSRT program was based on the protocol which had previously been shown more effective than stretching for PHP [103]. Both groups performed standing heel raises, however the experimental group were instructed to perform the exercise with the load as heavy as possible but no heavier than 8RM and for as many sets as possible. Participants in the control group were instructed to perform the exercise according to a rigid protocol progressing from 12RM to 8RM. Both groups performed exercises every second day during the 12-week intervention. If participants felt they could perform more repetitions than their load corresponded to (e.g., 10 repetitions when the load was supposed to be 8RM), a backpack with books to add weight was used. There was no significant between-group difference in the improvement of Foot Health Status Questionnaire pain after 12 weeks (adjusted MD 26.9 points, 95\% CI 215.5 to 1.7). According to the Global Rating of Change, 24 of 33 in the experimental group and 20 of 32 in the control group were improved $(R R=1.16,95 \%$ CI 0.83 to 1.64$)$. However, only four participants achieved Patient Acceptable Symptom State, suggesting more comprehensive interventions are warranted. Although tendinopathy loading programs are typically pre-determined, this study indicates that standardised programs are unnecessary if self-dosed programs aiming to maximise load are equally effective [26].

Similarly, Stevens and Tan [296] found that performing a 6-weeks do-as-tolerated program of the Alfredson eccentric heel-drop exercises led to similar outcomes in Achilles tendinopathy pain and function compared to the standardised 180 repetitions per day protocol. Twenty-eight patients were randomized to either the standard $(n=15)$ or the do-as-tolerated $(n=13) 6$-week intervention protocol. The standard group performed 180 repetitions a day, by completing 3 sets of 15 repetitions in 2 training positions (knee fully extended and knee slightly flexed) twice a day. The do-as-tolerated group also completed the eccentric heel-drop 
exercises in both training positions twice a day, with the recommendation that they achieve a repetition volume similar to that of the standard group, but they were also told that they could choose to complete a repetition volume that was tolerable. Apart from repetition volume, all other aspects of management were standardized between groups. There was a statistically significant within-group improvement in function for both groups (standard, $P=.03$; do as tolerated, $P<.001)$ and pain for the do-as-tolerated group $(P=.001)$ at week 6 , based on the intention-to-treat analysis. There was a statistically significant between-group difference in VISA-A scores at week 3 , based on both the intention-to-treat $(P=$ .004) and per-protocol analyses $(P=.007)$, partly due to a within-group deterioration at week 3 in the standard group. There were no statistically significant between-group differences at the completion of the intervention. The mean numbers of repetitions completed per day by the participants were 112 (95\% confidence interval [CI]: 85, 139) and 166 (95\% CI: 150, 182) for the doas-tolerated and standard groups, respectively [296].

Contrary to expectation, the self-dosed HSRT groups in both studies did not substantially increase the achieved exercise dose compared with a pre-determined regimen. Riel et al. [26] concluded that these HSRT regimens are not enough to achieve acceptable symptom state in most people with PHP. Perhaps this is because heel-raise HSRT alone does not cater for deficits in a patient's entire strength spectrum, with the addition of other exercise types such as kinetic chain and plyometric exercise being needed to address strength deficits. The use of a 'as many sets or repetitions as possible' method did not increase the number of sets performed in the self-dosed groups compared to the pre-determined groups. Perhaps the use of a RIR-based RPE method of autoregulation could be a potential strategy to ensure that an adequate and optimal amount of load is achieved and progressed for each individual patient undertaking HSRT interventions. The use of RPE to dictate the number of repetitions and sets performed as a method of volume autoregulation has been found effective to increase total volume and strength gains within powerlifting athletes but has not been investigated for increasing strength in tendinopathy rehabilitation [30]. 


\section{Practical Application}

Although the previously described autoregulated HSRT protocols $[26,296]$ were innovative approaches to attempt to improve upon the earlier protocols of Alfredson and Rathleff by allowing individualised modification, patients did not perform an increased number of sets or repetitions, nor increased load. Perhaps set progression by a RIR approach would be preferable to performing as many sets or repetitions as possible. This could also allow for within-session increases in load, accounting for an individual's daily readiness to train and their own individual factors. The intra-session changes and load achieved due to RIR monitoring, could then be used to determine future daily load selection and weekly adjustment. For example, in the self-dosed Riel protocol, the target was to perform 8RM as heavy as possible for as many sets as possible at a specific load. However, if the patient was to record a 10RIR on the first set, then load could be lowered to ensure completion of the intended training volume. Intra-session external load adjustments could also be made using the RIR scale based upon pre-determined RIR goals. For example, if a target RIR is set at 5-6 and a RIR of 7 is recorded, a $2.5 \mathrm{~kg}$ load decrease could occur, and for a RIR of 9, a $5 \mathrm{~kg}$ load decrease. Similarly, a RIR of 3-5 would require an adjustment of $2.5 \mathrm{~kg}$ increase in load, and an RIR of 1-2, a $5 \mathrm{~kg}$ increase (Table 4).

Following an initial set at a load determined by the previous session, sets 2-5 can be adapted in load based on RIR, with the load in the fifth set determining the starting load of the next session, as in the earlier APRE protocols. Many tendinopathy resistance training protocols stipulate an increase of load increments of $2.5-5 \mathrm{~kg}$ between sessions if there is no increase in pain. Adopting this intrasession autoregulated approach based on RIR would allow for individualised loading in response to an individual's daily readiness to train and their individual factors. This individualised approach to load adjustment may allow for more specific load progression than the standardised protocols which do not adjust load within sessions, potentially improving individuals' outcomes to the intervention. Rest could also be autoregulated, as this has been shown no less effective than pre-determined rest protocols for increasing strength and hypertrophy [233]. A 
comparison of how this theoretical autoregulated protocol would compare to the Rathleff and Riel protocols for PHP is presented in table 5. The example provided is specific to HSRT for PHP, with autoregulation methods requiring feasibility and effectiveness investigations across all lower limb tendinopathies.

Despite the potential efficacy of such an autoregulation approach in tendinopathy, several potential limitations to its practical application exist. Although this theoretical autoregulated protocol only includes a progressive HSRT heel-raise exercise, future interventional studies should also consider adding plyometric exercises and exercises with high kinetic chain activation such as squats and deadlifts, progressed in the same autoregulated manner, to address potential strength spectrum deficits [142, 297]. Accurate use of RPE scales has been shown to be higher in those with more training experience and practice is required to become competent in using this method [228]. It may therefore be initially more applicable to well-trained athletes with tendinopathy, who have previous resistance training experience. The use of the previous sessions loading parameters to dictate the starting load for following sessions, does not consider daily readiness, which needs to be monitored at an individual level by each patient. Due to higher fatigue levels on any given day, the starting load may need to be subjectively reduced, which again will require experience to become proficient in making such judgements. Initial supervision and guidance by a physiotherapist with knowledge of resistance training and autoregulation principles, may enhance the safety and efficacy of implementing the autoregulation methods, particularly with patients who have little or no resistance training experience. The use of an RPE RIR progression method will naturally have an element of unreliability due to its subjectivity and objective autoregulation methods such as VBT have been found slightly more effective when compared against each other [255]. However, its advantages include easier implementation while also being a potential method for increasing patient self-efficacy and allowing self-management in the home setting without the need for expensive equipment, making it a more practical and costeffective choice. 
Table 4: Theoretical load adjustment during autoregulated tendinopathy heel-raise resistance training based on representation of rating of percieved exertion and corresponding repeitions in reserve vales.

Warm-up if required

Set 1: Based on load lifted during last set of last session

Set 2-4: Load adjusted per set based on RPE/RIR values during previous set

\begin{tabular}{llll}
\hline RPE & RIR & Description of perceived effort & $\begin{array}{l}\text { Example load } \\
\text { adjustment }\end{array}$ \\
\hline 10 & 0 & $\begin{array}{l}\text { Maximum effort, cannot increase load or } \\
\text { repetitions }\end{array}$ & $-5 \mathrm{~kg}$ \\
9.5 & 0.5 & $\begin{array}{l}\text { Cannot complete more repetitions but } \\
\text { could increase load }\end{array}$ & $-2.5 \mathrm{~kg}$ \\
9 & 1 & 1 repetition remaining & Maintain load \\
8.5 & 1.5 & $1-2$ repetitions remaining & Maintain load \\
8 & 2 & 2 repetitions remaining & + Maintain load \\
7.5 & 2.5 & $2-3$ repetitions remaining & $+2.5 \mathrm{~kg}$ \\
7 & 3 & 3 repetitions remaining & $+2.5 \mathrm{~kg}$ \\
$5-6$ & $4-6$ & $4-6$ repetitions remaining & $+5 \mathrm{~kg}$ \\
$3-4$ & $6+$ & Light effort & $+7.5 \mathrm{~kg}$ \\
$1-2$ & $10+$ & Little to no effort & $+10 \mathrm{~kg}$ \\
\hline
\end{tabular}


Table 5: Descriptors of Rathleff, Riel and Autoregulated interventions

\begin{tabular}{|c|c|c|c|}
\hline \multirow[t]{2}{*}{ Descriptor } & \multicolumn{3}{|c|}{ Exercise program } \\
\hline & Rathleff & Riel & Autoregulated \\
\hline Load magnitude & $\begin{array}{l}\text { Week 1+2: 12RM } \\
\text { Week 3+4: 10RM } \\
\text { Week 5-12: } 8 \text { RM }\end{array}$ & $\begin{array}{l}\text { As heavy as possible, } \\
\text { no heavier than } 8 \mathrm{RM}\end{array}$ & 8RM \\
\hline Monitoring per set & Not reported & Not reported & $\begin{array}{l}\text { RPE RIR scale - adjust } \\
\text { load based on response }\end{array}$ \\
\hline $\begin{array}{l}\text { Load progression and } \\
\text { volume }\end{array}$ & $\begin{array}{l}\text { Increase weight in } \\
\text { backpack - not } \\
\text { recorded }\end{array}$ & $\begin{array}{l}\text { Increase weight in } \\
\text { backpack - not } \\
\text { recorded }\end{array}$ & $\begin{array}{l}\text { Adjust weight per set } \\
\text { based on RPE RIR scale } \\
\text { - record weight }\end{array}$ \\
\hline $\begin{array}{l}\text { Number of repetitions } \\
\text { per set }\end{array}$ & $\begin{array}{l}\text { Week 1+2: } 12 \\
\text { Week 3+4: } 10 \\
\text { Week 5-12: } 8\end{array}$ & 8 , depending on load & 8 \\
\hline Number of sets & $\begin{array}{l}\text { Week 1+2: } 3 \\
\text { Week 3+4: } 4 \\
\text { Week 5-12: } 5\end{array}$ & As many as possible & 5 \\
\hline Rest between sets & 2 minutes & 2 minutes & As much as needed \\
\hline Session frequency & \multicolumn{3}{|c|}{ 3/week } \\
\hline Program duration & \multicolumn{3}{|c|}{12 weeks } \\
\hline $\begin{array}{l}\text { Contraction modes } \\
\text { per repetition }\end{array}$ & \multicolumn{3}{|c|}{3 seconds concentric, 2 seconds isometric, 3 seconds eccentric } \\
\hline $\begin{array}{l}\text { Rest between } \\
\text { repetitions }\end{array}$ & \multicolumn{3}{|c|}{ Nil } \\
\hline Time under tension & $\begin{array}{l}\text { Week 1-2: } 8 \\
\text { s/repetition, } 96 \\
\text { s/set, } 288 \text { s/training } \\
\text { session } \\
\text { Week } 3-4: 8 \\
\text { s/repetition, } \\
80 \text { s/set, } 320 \\
\text { s/training session } \\
\text { Week 5-12: } 8 \\
\text { s/repetition, } \\
64 \text { s/set, } 320 \\
\text { s/training session } \\
\text { Total over } 12 \text { weeks: } \\
13216 \text { s }\end{array}$ & $\begin{array}{l}8 \text { s/repetition, } 64 \\
\text { s/set, Total over } 12 \\
\text { weeks: varies } \\
\text { between participants } \\
\text { depending on number } \\
\text { of sets performed }\end{array}$ & $\begin{array}{l}8 \mathrm{~s} / \text { repetition, } 64 \mathrm{~s} / \mathrm{set} \text {, } \\
320 \text { s/training session } \\
\text { Total over } 12 \text { weeks: } \\
13440 \mathrm{~s}\end{array}$ \\
\hline Muscle failure & Yes & Yes & Not mandatory \\
\hline Range of motion & \multicolumn{3}{|c|}{ Full range of motion } \\
\hline $\begin{array}{l}\text { Between session } \\
\text { recovery }\end{array}$ & \multicolumn{3}{|c|}{48 hours } \\
\hline Exercise description & \multicolumn{3}{|c|}{$\begin{array}{l}\text { Standing heel raise, with forefoot on a step and a towel placed } \\
\text { underneath the toes to dorsiflex them throughout the exercise. With a } \\
\text { fully extended knee, the participant performed a heel raise }\end{array}$} \\
\hline
\end{tabular}




\section{Conclusion}

This review has provided an overview of individual factors in tendinopathy, current resistance training protocols in lower limb tendinopathy and their limitations, and autoregulation methods, culminating in a proposed example of the implementation of autoregulation within current tendinopathy HSRT protocols. While current resistance training protocols are considered the gold standard treatment intervention for a range of tendinopathies, they are not without limitations as they fail to address an individuals entire strength spectrum and the principle of individualisation, resulting in inadequate long-term outcomes. This review provides an example of how these factors may be addressed through autoregulation methods, which may improve outcomes for tendinopathy, which is a leading global cause of musculoskeletal pain and disability. Previous literature has demonstrated how the adoption of autoregulation methods in resistance training can improve strength gains and sports performance in healthy athletes. However, there has been a dearth of research applying these autoregulation principles to musculoskeletal rehabilitation, despite the methodology originating in physiotherapy research. This review demonstrates how applying these autoregulation methods to widely adopted resistance training protocols in tendinopathy, allows for tailoring the exercise dosage and considering the myriad of potential patient individual factors which are not accounted for in standardised and pre-determined protocols. Further interventional research is required to investigate the safety, feasibility and efficacy of these methods in improving outcomes of resistance training interventions in tendinopathy rehabilitation.

A key point from this review is not that autoregulation should be used as a replacement for current interventions, but that it is a context-specific approach and may be used as a modification strategy to the current resistance training protocols in tendinopathy. Eccentric only and HSRT protocols have been successfully implemented in lower limb tendinopathy rehabilitation around the world for two decades. However, despite their moderate success, modification through improved prescription, monitoring and progression based on the principle of individualisation may lead to more optimal, individually tailored and efficacious interventions. For several years, leading tendinopathy clinicians and researchers 
have been advocating that tendinopathy rehabilitation must be individualised to improve long-term outcomes. However, this has not been addressed, with predetermined and standardised protocols remaining the mainstay of tendinopathy rehabilitation, both clinically and in interventional research methods. Its clear from recent literature that a paradigm shift in resistance training application in lower limb tendinopathy is required, in order to attempt to improve clinical outcomes for patients, which remain inadequate in the long-term. Perhaps slight adaption of these long-standing resistance training interventions through autoregulation methods, may pave the way forward for ascertaining the most optimal and efficacious approach for tendinopathy rehabilitation, which has yet to be elucidated.

Funding: No sources of funding were used to assist in the preparation of this article.

Conflicts of interest/Competing interests: The author declares no conflicts of interest relevant to the content of this review.

Authorship contributions: IB conceptualised the work, wrote the first draft of the manuscript, revised the manuscript and approved the final manuscript. 


\section{References}

1. Smith E, Hoy DG, Cross M, Vos T, Naghavi M, Buchbinder R, et al. The global burden of other musculoskeletal disorders: Estimates from the global burden of disease 2010 study. Ann Rheum Dis. 2014 Aug;73(8):1462-9.

2. Hoy DG, Smith E, Cross M, Sanchez-Riera L, Blyth FM, Buchbinder R, et al. Reflecting on the global burden of musculoskeletal conditions: Lessons learnt from the global burden of disease 2010 study and the next steps forward. Ann Rheum Dis. 2015 Jan;74(1):4-7.

3. Onuora S. Burden of musculoskeletal diseases increasing. Nat Rev Rheumatol. 2019 Jun;15(6):318,019-0232-8.

4. Vavken P, Dorotka R. Burden of musculoskeletal disease and its determination by urbanicity, socioeconomic status, age, and sex: Results from 14,507 subjects. Arthritis Care Res (Hoboken). 2011 Nov;63(11):1558-64.

5. Moraes VY, Lenza M, Tamaoki MJ, Faloppa F, Belloti JC. Platelet-rich therapies for musculoskeletal soft tissue injuries. Cochrane Database Syst Rev. 2014 Apr 29;(4):CD010071. doi(4):CD010071.

6. Maffulli N, Wong J, Almekinders LC. Types and epidemiology of tendinopathy. Clin Sports Med. 2003 Oct;22(4):675-92.

7. Dos Santos Franco YR, Miyamoto GC, Franco KFM, de Oliveira RR, Cabral CMN. Exercise therapy in the treatment of tendinopathies of the lower limbs: A protocol of a systematic review. Syst Rev. 2019 Jun 15;8(1):142,019-1058-9.

8. Fu SC, Rolf C, Cheuk YC, Lui PP, Chan KM. Deciphering the pathogenesis of tendinopathy: A three-stages process. Sports Med Arthrosc Rehabil Ther Technol. 2010 Dec $13 ; 2: 30,2555-2-30$.

9. Magnussen RA, Dunn WR, Thomson AB. Nonoperative treatment of midportion achilles tendinopathy: A systematic review. Clin J Sport Med. 2009 Jan;19(1):5464. 
10. Magnusson SP, Kjaer M. The impact of loading, unloading, ageing and injury on the human tendon. J Physiol. 2019 Mar;597(5):1283-98.

11. Lui PP, Maffulli N, Rolf C, Smith RK. What are the validated animal models for tendinopathy? Scand J Med Sci Sports. 2011 Feb;21(1):3-17.

12. Simpson M, Rio E, Cook J. At what age do children and adolescents develop lower limb tendon pathology or tendinopathy? A systematic review and metaanalysis. Sports Med. 2016 Apr;46(4):545-57.

13. Andres BM, Murrell GA. Treatment of tendinopathy: What works, what does not, and what is on the horizon. Clin Orthop Relat Res. 2008 Jul;466(7):1539-54.

14. Rui YF, Lui PP, Chan LS, Chan KM, Fu SC, Li G. Does erroneous differentiation of tendon-derived stem cells contribute to the pathogenesis of calcifying tendinopathy? Chin Med J (Engl). 2011 Feb;124(4):606-10.

15. Jarvinen TA, Kannus P, Maffulli N, Khan KM. Achilles tendon disorders: Etiology and epidemiology. Foot Ankle Clin. 2005 Jun;10(2):255-66.

16. Rees JD, Stride M, Scott A. Tendons--time to revisit inflammation. Br J Sports Med. 2014 Nov;48(21):1553-7

17. Sharma $P$, Maffulli N. Tendon injury and tendinopathy: Healing and repair. J Bone Joint Surg Am. 2005 Jan;87(1):187-202.

18. Ganestam A, Kallemose T, Troelsen A, Barfod KW. Increasing incidence of acute achilles tendon rupture and a noticeable decline in surgical treatment from 1994 to 2013. A nationwide registry study of 33,160 patients. Knee Surg Sports Traumatol Arthrosc. 2016 Dec;24(12):3730-7.

19. Abat F, Alfredson H, Cucchiarini M, Madry H, Marmotti A, Mouton C, et al. Current trends in tendinopathy: Consensus of the ESSKA basic science committee. part I: Biology, biomechanics, anatomy and an exercise-based approach. J Exp Orthop. 2017 Dec;4(1):18,017-0092-6. Epub 2017 May 30. 
20. Ahmad J, Repka M, Raikin SM. Treatment of myotendinous achilles ruptures. Foot Ankle Int. 2013 Aug;34(8):1074-8

21. Girgis B, Duarte JA. Physical therapy for tendinopathy: An umbrella review of systematic reviews and meta-analyses. Phys Ther Sport. 2020 Aug 11;46:30-46.

22. Cardoso TB, Pizzari T, Kinsella R, Hope D, Cook JL. Current trends in tendinopathy management. Best Pract Res Clin Rheumatol. 2019 Feb;33(1):12240.

23. Riel H, Olesen JL, Jensen MB, Vicenzino B, Rathleff MS. Heavy-slow resistance training in addition to an ultrasound-guided corticosteroid injection for individuals with plantar fasciopathy: A feasibility study. Pilot Feasibility Stud. 2019 Aug 24;5:105,019-0489-3. eCollection 2019.

24. Dimitrios S. Exercise for tendinopathy. World J Methodol. 2015 Jun $26 ; 5(2): 51-4$.

25. Rathleff MS, Thorborg K. 'Load me up, scotty': Mechanotherapy for plantar fasciopathy (formerly known as plantar fasciitis). $\mathrm{Br}$ J Sports Med. 2015 May;49(10):638-9.

26. Riel H, Jensen MB, Olesen JL, Vicenzino B, Rathleff MS. Self-dosed and predetermined progressive heavy-slow resistance training have similar effects in people with plantar fasciopathy: A randomised trial. J Physiother. 2019 Jul;65(3): 144-51.

27. Fleck SJ. Non-linear periodization for general fitness \& athletes. J Hum Kinet. 2011 Sep;29A:41-5.

28. Mann JB, Thyfault JP, Ivey PA, Sayers SP. The effect of autoregulatory progressive resistance exercise vs. linear periodization on strength improvement in college athletes. J Strength Cond Res. 2010 Jul;24(7):1718-23.

29. Steinmann S, Pfeifer CG, Brochhausen C, Docheva D. Spectrum of tendon pathologies: Triggers, trails and end-state. Int J Mol Sci. 2020 Jan 28;21(3):10.3390/ijms21030844. 
30. Helms ER, Cross MR, Brown SR, Storey A, Cronin J, Zourdos MC. Rating of perceived exertion as a method of volume autoregulation within a periodized program. J Strength Cond Res. 2018 Jun;32(6):1627-36.

31. Seitz AL, McClure PW, Finucane S, Boardman ND,3rd, Michener LA. Mechanisms of rotator cuff tendinopathy: Intrinsic, extrinsic, or both? Clin Biomech (Bristol, Avon). 2011 Jan;26(1):1-12.

32. Deans VM, Miller A, Ramos J. A prospective series of patients with chronic achilles tendinopathy treated with autologous-conditioned plasma injections combined with exercise and therapeutic ultrasonography. J Foot Ankle Surg. 2012 Nov-Dec;51(6):706-10.

33. Wu F, Nerlich M, Docheva D. Tendon injuries: Basic science and new repair proposals. EFORT Open Rev. 2017 Jul 27;2(7):332-42.

34. Moosmayer S, Smith HJ, Tariq R, Larmo A. Prevalence and characteristics of asymptomatic tears of the rotator cuff: An ultrasonographic and clinical study. J Bone Joint Surg Br. 2009 Feb;91(2):196-200.

35. Andrew G, Jonathan S. Comparison of achilles tendon loading between male and female recreational runners. J Hum Kinet. 2014 Dec 30;44:155-9.

36. Clayton RA, Court-Brown CM. The epidemiology of musculoskeletal tendinous and ligamentous injuries. Injury. 2008 Dec;39(12):1338-44.

37. Ferreira VMLM, Oliveira RR, Nazareno TS, Freitas LV, Mendonca LD. Interaction of foot and hip factors identifies achilles tendinopathy occurrence in recreational runners. Phys Ther Sport. 2020 Sep;45:111-9.

38. Dean BJF, Dakin SG, Millar NL, Carr AJ. Review: Emerging concepts in the pathogenesis of tendinopathy. Surgeon. 2017 Dec;15(6):349-54.

39. Benjamin M, Kaiser E, Milz S. Structure-function relationships in tendons: $A$ review. J Anat. 2008 Mar;212(3):211-28.

40. Sharma $P$, Maffulli N. Tendinopathy and tendon injury: The future. Disabil Rehabil. 2008;30(20-22):1733-45. 
41. Harris M, Schultz A, Drew MK, Rio E, Adams S, Edwards S. Thirty-seven jumplanding biomechanical variables are associated with asymptomatic patellar tendon abnormality and patellar tendinopathy: A systematic review. Phys Ther Sport. 2020 Sep;45:38-55.

42. Leblanc DR, Schneider M, Angele P, Vollmer G, Docheva D. The effect of estrogen on tendon and ligament metabolism and function. J Steroid Biochem Mol Biol. 2017 Sep; 172:106-16.

43. Kjaer M, Langberg $H$, Heinemeier $K$, Bayer ML, Hansen M, Holm L, et al. From mechanical loading to collagen synthesis, structural changes and function in human tendon. Scand J Med Sci Sports. 2009 Aug;19(4):500-10.

44. Kjaer M, Magnusson P, Krogsgaard M, Boysen Moller J, Olesen J, Heinemeier $\mathrm{K}$, et al. Extracellular matrix adaptation of tendon and skeletal muscle to exercise. J Anat. 2006 Apr;208(4):445-50.

45. Knobloch K. Drug-induced tendon disorders. Adv Exp Med Biol. 2016;920:22938.

46. van der Linden PD, Sturkenboom MC, Herings RM, Leufkens HG, Stricker BH. Fluoroquinolones and risk of achilles tendon disorders: Case-control study. BMJ. 2002 Jun $1 ; 324(7349): 1306-7$.

47. O'Keeffe M, Cullinane P, Hurley J, Leahy I, Bunzli S, O'Sullivan PB, et al. What influences patient-therapist interactions in musculoskeletal physical therapy? qualitative systematic review and meta-synthesis. Phys Ther. 2016 May;96(5):609-22.

48. Mallows A, Debenham J, Walker T, Littlewood C. Association of psychological variables and outcome in tendinopathy: A systematic review. Br J Sports Med. 2017 May;51(9): 743-8.

49. Mallows AJ, Debenham JR, Malliaras P, Stace R, Littlewood C. Cognitive and contextual factors to optimise clinical outcomes in tendinopathy. $\mathrm{Br}$ J Sports Med. 2017 Oct 9. 
50. Mc Auliffe S, Synott A, Casey H, Mc Creesh K, Purtill H, O'Sullivan K. Beyond the tendon: Experiences and perceptions of people with persistent achilles tendinopathy. Musculoskelet Sci Pract. 2017 Jun;29:108-14.

51. Cook JL, Docking SI. "Rehabilitation will increase the 'capacity' of your ...insert musculoskeletal tissue here...." defining 'tissue capacity': A core concept for clinicians. Br J Sports Med. 2015 Dec;49(23):1484-5.

52. Silbernagel KG, Thomee R, Eriksson BI, Karlsson J. Full symptomatic recovery does not ensure full recovery of muscle-tendon function in patients with achilles tendinopathy. Br J Sports Med. 2007 Apr;41(4):276,80; discussion 280.

53. Kongsgaard M, Qvortrup K, Larsen J, Aagaard P, Doessing S, Hansen $P$, et al. Fibril morphology and tendon mechanical properties in patellar tendinopathy: Effects of heavy slow resistance training. Am J Sports Med. 2010 Apr;38(4):74956.

54. Littlewood C, Ashton J, Mawson S, May S, Walters S. A mixed methods study to evaluate the clinical and cost-effectiveness of a self-managed exercise programme versus usual physiotherapy for chronic rotator cuff disorders: Protocol for the SELF study. BMC Musculoskelet Disord. 2012 Apr 30;13:62,2474-13-62.

55. Raschhofer R, Poulios N, Schimetta W, Kisling R, Mittermaier C. Early active rehabilitation after arthroscopic rotator cuff repair: A prospective randomized pilot study. Clin Rehabil. 2017 Oct;31(10):1332-9.

56. Dejaco B, Habets B, van Loon C, van Grinsven S, van Cingel R. Eccentric versus conventional exercise therapy in patients with rotator cuff tendinopathy: $A$ randomized, single blinded, clinical trial. Knee Surg Sports Traumatol Arthrosc. 2017 Jul;25(7):2051-9.

57. Gillespie MA, M Cznik A, Wassinger CA, Sole G. Rotator cuff-related pain: Patients' understanding and experiences. Musculoskelet Sci Pract. 2017 Aug; 30:64-71.

58. Hanratty CE, Kerr DP, Wilson IM, McCracken M, Sim J, Basford JR, et al. Physical therapists' perceptions and use of exercise in the management of 
subacromial shoulder impingement syndrome: Focus group study. Phys Ther. 2016 Sep;96(9):1354-63.

59. Ingwersen KG, Jensen $S L$, Sorensen $L$, Jorgensen $H R$, Christensen $R$, Sogaard $K$, et al. Three months of progressive high-load versus traditional low-load strength training among patients with rotator cuff tendinopathy: Primary results from the double-blind randomized controlled RoCTEx trial. Orthop J Sports Med. 2017 Aug 28;5(8):2325967117723292.

60. Plinsinga ML, Coombes BK, Mellor R, Vicenzino B. Individuals with persistent greater trochanteric pain syndrome exhibit impaired pain modulation, as well as poorer physical and psychological health, compared with pain-free individuals: A cross-sectional study. Pain Med. 2020 Mar 31.

61. Thiese MS, Hegmann KT, Kapellusch J, Merryweather A, Bao S, Silverstein B, et al. Psychosocial factors related to lateral and medial epicondylitis: Results from pooled study analyses. J Occup Environ Med. 2016 Jun;58(6):588-93.

62. Andia I, Maffulli N. Blood-derived products for tissue Repair/Regeneration. Int J Mol Sci. 2019 Sep 17;20(18):10.3390/ijms20184581.

63. Pickering C, Kiely J. Do non-responders to exercise exist-and if so, what should we do about them? Sports Med. 2019 Jan;49(1):1-7.

64. Abate M, Di Carlo L, Belluati A, Salini V. Factors associated with positive outcomes of platelet-rich plasma therapy in achilles tendinopathy. Eur J Orthop Surg Traumatol. 2020 Jul;30(5):859-67.

65. Maestroni L, Read P, Bishop C, Papadopoulos K, Suchomel TJ, Comfort P, et al. The benefits of strength training on musculoskeletal system health: Practical applications for interdisciplinary care. Sports Med. 2020 Aug;50(8):1431-50.

66. Hainline B, Turner JA, Caneiro JP, Stewart M, Lorimer Moseley G. Pain in elite athletes-neurophysiological, biomechanical and psychosocial considerations: A narrative review. Br J Sports Med. 2017 Sep;51(17):1259-64. 
67. Rio E, Kidgell D, Purdam C, Gaida J, Moseley GL, Pearce AJ, et al. Isometric exercise induces analgesia and reduces inhibition in patellar tendinopathy. $\mathrm{Br} \mathrm{J}$ Sports Med. 2015 Oct;49(19):1277-83.

68. Rio E, Kidgell D, Moseley GL, Cook J. Elevated corticospinal excitability in patellar tendinopathy compared with other anterior knee pain or no pain. Scand J Med Sci Sports. 2016 Sep;26(9):1072-9

69. Plinsinga $M L$, Brink MS, Vicenzino $B$, van Wilgen $C P$. Evidence of nervous system sensitization in commonly presenting and persistent painful tendinopathies: A systematic review. J Orthop Sports Phys Ther. 2015 Nov;45(11):864-75.

70. Plinsinga $M L$, van Wilgen $C P$, Brink MS, Vuvan V, Stephenson A, Heales $L$, et al. Patellar and achilles tendinopathies are predominantly peripheral pain states: A blinded case control study of somatosensory and psychological profiles. $\mathrm{Br} \mathrm{J}$ Sports Med. 2018 Mar;52(5):284-91.

71. Sanchis MN, Lluch E, Nijs J, Struyf F, Kangasperko M. The role of central sensitization in shoulder pain: A systematic literature review. Semin Arthritis Rheum. 2015 Jun;44(6):710-6.

72. Littlewood C, Malliaras P, Bateman M, Stace R, May S, Walters S. The central nervous system--an additional consideration in 'rotator cuff tendinopathy' and a potential basis for understanding response to loaded therapeutic exercise. Man Ther. 2013 Dec;18(6):468-72.

73. Silbernagel KG. Does one size fit all when it comes to exercise treatment for achilles tendinopathy? J Orthop Sports Phys Ther. 2014 Feb;44(2):42-4.

74. Pizzolato C, Lloyd DG, Zheng MH, Besier TF, Shim VB, Obst SJ, et al. Finding the sweet spot via personalised achilles tendon training: The future is within reach. $\mathrm{Br}$ J Sports Med. 2019 Jan;53(1):11-2.

75. Rowe V, Hemmings S, Barton C, Malliaras P, Maffulli N, Morrissey D. Conservative management of midportion achilles tendinopathy: A mixed methods 
study, integrating systematic review and clinical reasoning. Sports Med. 2012 Nov $1 ; 42(11): 941-67$.

76. Peters JA, Zwerver J, Diercks RL, Elferink-Gemser MT, van den Akker-Scheek I. Preventive interventions for tendinopathy: A systematic review. J Sci Med Sport. 2016 Mar;19(3):205-11.

77. Kulig K, Noceti-DeWit LM, Reischl SF, Landel RF. Physical therapists' role in prevention and management of patellar tendinopathy injuries in youth, collegiate, and middle-aged indoor volleyball athletes. Braz J Phys Ther. 2015 SepOct; 19(5):410-20.

78. Cook JL, Purdam CR. The challenge of managing tendinopathy in competing athletes. Br J Sports Med. 2014 Apr;48(7):506-9.

79. Cook J. Tendinopathy: No longer a 'one size fits all' diagnosis. Br J Sports Med. 2011 Apr;45(5):385.

80. Morgan S, Janse van Vuuren EC, Coetzee F. Patellar tendinopathy: an international e-Delphi perspective. SAJR SPER. 2018;40(2):115-128.

81. Morrissey D. Guidelines and pathways for clinical practice in tendinopathy: Their role and development. J Orthop Sports Phys Ther. 2015 Nov;45(11):81922.

82. Cook JL, Purdam CR. Is tendon pathology a continuum? A pathology model to explain the clinical presentation of load-induced tendinopathy. $\mathrm{Br} \mathrm{J}$ Sports Med. 2009 Jun;43(6):409-16.

83. Cook JL, Rio E, Purdam CR, Docking SI. Revisiting the continuum model of tendon pathology: What is its merit in clinical practice and research? $\mathrm{Br} \mathrm{J}$ Sports Med. 2016 Oct;50(19):1187-91.

84. September AV, Posthumus M, van der Merwe L, Schwellnus M, Noakes TD, Collins $M$. The COL12A1 and COL14A1 genes and achilles tendon injuries. Int J Sports Med. 2008 Mar;29(3):257-63. 
85. Malliaras P, Purdam C, Maffulli N, Cook J. Temporal sequence of greyscale ultrasound changes and their relationship with neovascularity and pain in the patellar tendon. Br J Sports Med. 2010 Oct;44(13):944-7.

86. Malliaras $\mathrm{P}$, Cook J. Changes in anteroposterior patellar tendon diameter support a continuum of pathological changes. $\mathrm{Br} J$ Sports Med. 2011 Oct;45(13): 1048-51.

87. Stanish WD, Rubinovich RM, Curwin S. Eccentric exercise in chronic tendinitis. Clin Orthop Relat Res. 1986 Jul;(208)(208):65-8.

88. Alfredson $H$, Pietila $T$, Jonsson $P$, Lorentzon R. Heavy-load eccentric calf muscle training for the treatment of chronic achilles tendinosis. Am J Sports Med. 1998 May-Jun;26(3):360-6.

89. Malliaras $\mathrm{P}$, Barton CJ, Reeves ND, Langberg $\mathrm{H}$. Achilles and patellar tendinopathy loading programmes : A systematic review comparing clinical outcomes and identifying potential mechanisms for effectiveness. Sports Med. 2013 Apr;43(4):267-86.

90. Sayana MK, Maffulli N. Eccentric calf muscle training in non-athletic patients with achilles tendinopathy. J Sci Med Sport. 2007 Feb;10(1):52-8.

91. Visnes $H$, Bahr R. The evolution of eccentric training as treatment for patellar tendinopathy (jumper's knee): A critical review of exercise programmes. $\mathrm{Br} \mathrm{J}$ Sports Med. 2007 Apr;41(4):217-23.

92. Young MA, Cook JL, Purdam CR, Kiss ZS, Alfredson H. Eccentric decline squat protocol offers superior results at 12 months compared with traditional eccentric protocol for patellar tendinopathy in volleyball players. $\mathrm{Br}$ J Sports Med. 2005 Feb;39(2):102-5.

93. Couppe C, Svensson RB, Silbernagel KG, Langberg H, Magnusson SP. Eccentric or concentric exercises for the treatment of tendinopathies? J Orthop Sports Phys Ther. 2015 Nov;45(11):853-63. 
94. Mafi N, Lorentzon R, Alfredson H. Superior short-term results with eccentric calf muscle training compared to concentric training in a randomized prospective multicenter study on patients with chronic achilles tendinosis. Knee Surg Sports Traumatol Arthrosc. 2001;9(1):42-7.

95. Jonsson P, Alfredson H. Superior results with eccentric compared to concentric quadriceps training in patients with jumper's knee: A prospective randomised study. Br J Sports Med. 2005 Nov;39(11):847-50.

96. Peterson M, Butler S, Eriksson M, Svardsudd K. A randomized controlled trial of eccentric vs. concentric graded exercise in chronic tennis elbow (lateral elbow tendinopathy). Clin Rehabil. 2014 Sep;28(9):862-72.

97. Mendonca LM, Leite HR, Zwerver J, Henschke N, Branco G, Oliveira VC. How strong is the evidence that conservative treatment reduces pain and improves function in individuals with patellar tendinopathy? A systematic review of randomised controlled trials including GRADE recommendations. Br J Sports Med. 2020 Jan;54(2):87-93.

98. Murphy MC, Travers MJ, Chivers P, Debenham JR, Docking SI, Rio EK, et al. Efficacy of heavy eccentric calf training for treating mid-portion achilles tendinopathy: A systematic review and meta-analysis. $\mathrm{Br}$ J Sports Med. 2019 Sep;53(17):1070-7.

99. Lim HY, Wong SH. Effects of isometric, eccentric, or heavy slow resistance exercises on pain and function in individuals with patellar tendinopathy: A systematic review. Physiother Res Int. 2018 Oct;23(4):e1721.

100. Silbernagel KG, Hanlon S, Sprague A. Current clinical concepts: Conservative management of achilles tendinopathy. J Athl Train. 2020 May;55(5):438-47.

101. Kongsgaard M, Kovanen V, Aagaard P, Doessing S, Hansen P, Laursen AH, et al. Corticosteroid injections, eccentric decline squat training and heavy slow resistance training in patellar tendinopathy. Scand J Med Sci Sports. 2009 Dec; 19(6): 790-802. 
102. Beyer R, Kongsgaard M, Hougs Kjaer B, Ohlenschlaeger T, Kjaer M, Magnusson SP. Heavy slow resistance versus eccentric training as treatment for achilles tendinopathy: A randomized controlled trial. Am J Sports Med. 2015 Jul;43(7): 1704-11.

103. Rathleff MS, Molgaard CM, Fredberg U, Kaalund S, Andersen KB, Jensen TT, et al. High-load strength training improves outcome in patients with plantar fasciitis: A randomized controlled trial with 12-month follow-up. Scand J Med Sci Sports. 2015 Jun;25(3):e292-300.

104. Murtaugh B, Ihm JM. Eccentric training for the treatment of tendinopathies. Curr Sports Med Rep. 2013 May-Jun;12(3):175-82.

105. Khan KM, Scott A. Mechanotherapy: How physical therapists' prescription of exercise promotes tissue repair. Br J Sports Med. 2009 Apr;43(4):247-52.

106. Farnqvist K, Pearson S, Malliaras P. Adaptation of tendon structure and function in tendinopathy with exercise and its relationship to clinical outcome. J Sport Rehab. 2020 01;29(1):107-15.

107. O'Sullivan K, McAuliffe S, Deburca N. The effects of eccentric training on lower limb flexibility: A systematic review. Br J Sports Med. 2012 Sep;46(12):83845.

108. Timmins RG, Ruddy JD, Presland J, Maniar N, Shield AJ, Williams MD, et al. Architectural changes of the biceps femoris long head after concentric or eccentric training. Med Sci Sports Exerc. 2016 Mar;48(3):499-508.

109. Weppler $\mathrm{CH}$, Magnusson SP. Increasing muscle extensibility: A matter of increasing length or modifying sensation? Phys Ther. 2010 Mar;90(3):438-49.

110. Freitas SR, Mil-Homens P. Effect of 8-week high-intensity stretching training on biceps femoris architecture. J Strength Cond Res. 2015 Jun;29(6):1737-40.

111. Konrad A, Tilp M. Increased range of motion after static stretching is not due to changes in muscle and tendon structures. Clin Biomech (Bristol, Avon). 2014 Jun;29(6):636-42. 
112. Askling CM, Tengvar M, Thorstensson A. Acute hamstring injuries in swedish elite football: A prospective randomised controlled clinical trial comparing two rehabilitation protocols. Br J Sports Med. 2013 Oct;47(15):953-9.

113. Barratt PA, Brookes N, Newson A. Conservative treatments for greater trochanteric pain syndrome: A systematic review. $\mathrm{Br}$ J Sports Med. 2017 Jan;51(2):97-104.

114. Paavola M, Kannus P, Paakkala T, Pasanen M, Jarvinen M. Long-term prognosis of patients with achilles tendinopathy. an observational 8-year followup study. Am J Sports Med. 2000 Sep-Oct;28(5):634-42.

115. Malliaras P, Cook J, Purdam C, Rio E. Patellar tendinopathy: Clinical diagnosis, load management, and advice for challenging case presentations. J Orthop Sports Phys Ther. 2015 Nov;45(11):887-98.

116. Kulig K, Lederhaus ES, Reischl S, Arya S, Bashford G. Effect of eccentric exercise program for early tibialis posterior tendinopathy. Foot Ankle Int. 2009 Sep;30(9):877-85.

117. Waugh CM, Alktebi T, de Sa A, Scott A. Impact of rest duration on achilles tendon structure and function following isometric training. Scand J Med Sci Sports. 2018 Feb;28(2):436-45.

118. Sussmilch-Leitch SP, Collins NJ, Bialocerkowski AE, Warden SJ, Crossley KM. Physical therapies for achilles tendinopathy: Systematic review and metaanalysis. J Foot Ankle Res. 2012 Jul 2;5(1):15,1146-5-15.

119. Silbernagel KG, Thomee R, Thomee $P$, Karlsson J. Eccentric overload training for patients with chronic achilles tendon pain--a randomised controlled study with reliability testing of the evaluation methods. Scand J Med Sci Sports. 2001 Aug;11(4):197-206.

120. van Ark M, Cook JL, Docking SI, Zwerver J, Gaida JE, van den Akker-Scheek $I$, et al. Do isometric and isotonic exercise programs reduce pain in athletes with patellar tendinopathy in-season? A randomised clinical trial. J Sci Med Sport. 2016 Sep; 19(9):702-6. 
121. Cuddeford T, Houck J, Palmer D, Beilstein J, Visser J. What maximum ankle torque is appropriate for training patients with non-insertional achilles tendinopathy. Orthopaedic Practice. 2018;30(4);543-547.

122. de Jonge S, de Vos RJ, Van Schie HT, Verhaar JA, Weir A, Tol JL. One-year follow-up of a randomised controlled trial on added splinting to eccentric exercises in chronic midportion achilles tendinopathy. Br J Sports Med. 2010 Jul;44(9):6737.

123. Vicenzino B. Tendinopathy: Evidence-informed physical therapy clinical reasoning. J Orthop Sports Phys Ther. 2015 Nov;45(11):816-8.

124. Stergioulas A, Stergioula M, Aarskog R, Lopes-Martins RA, Bjordal JM. Effects of low-level laser therapy and eccentric exercises in the treatment of recreational athletes with chronic achilles tendinopathy. Am J Sports Med. 2008 May;36(5):881-7.

125. Rompe JD, Furia J, Maffulli N. Eccentric loading versus eccentric loading plus shock-wave treatment for midportion achilles tendinopathy: A randomized controlled trial. Am J Sports Med. 2009 Mar;37(3):463-70.

126. Silbernagel KG, Thomee R, Eriksson BI, Karlsson J. Continued sports activity, using a pain-monitoring model, during rehabilitation in patients with achilles tendinopathy: A randomized controlled study. Am J Sports Med. 2007 Jun;35(6): 897-906.

127. Riel H, Vicenzino B, Jensen MB, Olesen JL, Holden S, Rathleff MS. The effect of isometric exercise on pain in individuals with plantar fasciopathy: A randomized crossover trial. Scand J Med Sci Sports. 2018 Sep 11.

128. Purdam CR, Jonsson $P$, Alfredson $H$, Lorentzon $R$, Cook JL, Khan KM. A pilot study of the eccentric decline squat in the management of painful chronic patellar tendinopathy. Br J Sports Med. 2004 Aug;38(4):395-7.

129. Arampatzis A, Mersmann F, Bohm S. Individualized muscle-tendon assessment and training. Front Physiol. 2020 Jun 26;11:723. 
130. Bohm S, Mersmann F, Arampatzis A. Human tendon adaptation in response to mechanical loading: A systematic review and meta-analysis of exercise intervention studies on healthy adults. Sports Med Open. 2015 Dec;1(1):7,0150009-9. Epub 2015 Mar 27.

131. Davies TB, Halaki M, Orr R, Helms ER, Hackett DA. Changes in bench press velocity and power after 8 weeks of high-load cluster- or traditional-set structures. J Strength Cond Res. 2020 Oct;34(10):2734-42.

132. Barton CJ, de Oliveira Silva D, Patterson BE, Crossley KM, Pizzari T, Nunes GS. A proximal progressive resistance training program targeting strength and power is feasible in people with patellofemoral pain. Phys Ther Sport. 2019 Jul;38:59-65.

133. Barton CJ, Lack S, Malliaras P, Morrissey D. Gluteal muscle activity and patellofemoral pain syndrome: A systematic review. $\mathrm{Br}$ J Sports Med. 2013 Mar;47(4):207-14.

134. Baldon Rde M, Piva SR, Scattone Silva R, Serrao FV. Evaluating eccentric hip torque and trunk endurance as mediators of changes in lower limb and trunk kinematics in response to functional stabilization training in women with patellofemoral pain. Am J Sports Med. 2015 Jun;43(6):1485-93.

135. Lack S, Barton C, Sohan O, Crossley K, Morrissey D. Proximal muscle rehabilitation is effective for patellofemoral pain: A systematic review with metaanalysis. Br J Sports Med. 2015 Nov;49(21):1365-76.

136. Mucha MD, Caldwell W, Schlueter EL, Walters C, Hassen A. Hip abductor strength and lower extremity running related injury in distance runners: A systematic review. J Sci Med Sport. 2017 Apr;20(4):349-55.

137. Meira EP, Brumitt J. Influence of the hip on patients with patellofemoral pain syndrome: A systematic review. Sports Health. 2011 Sep;3(5):455-65.

138. Rathleff MS, Rathleff CR, Crossley KM, Barton CJ. Is hip strength a risk factor for patellofemoral pain? A systematic review and meta-analysis. Br J Sports Med. 2014 Jul;48(14):1088,2013-093305. Epub 2014 Mar 31. 
139. Rio E, Mayes S, Cook J. Heel pain: A practical approach. Aust Fam Physician. 2015 Mar;44(3):96-101.

140. Cibulka MT, White DM, Woehrle J, Harris-Hayes M, Enseki K, Fagerson TL, et al. Hip pain and mobility deficits--hip osteoarthritis: Clinical practice guidelines linked to the international classification of functioning, disability, and health from the orthopaedic section of the american physical therapy association. J Orthop Sports Phys Ther. 2009 Apr;39(4):A1-25.

141. Delitto A, George SZ, Van Dillen LR, Whitman JM, Sowa G, Shekelle P, et al. Low back pain. J Orthop Sports Phys Ther. 2012 Apr;42(4):A1-57.

142. Reiman MP, Bolgla LA, Loudon JK. A literature review of studies evaluating gluteus maximus and gluteus medius activation during rehabilitation exercises. Physiother Theory Pract. 2012 May;28(4):257-68.

143. Nakagawa TH, Muniz TB, Baldon Rde M, Dias Maciel C, de Menezes Reiff RB, Serrao FV. The effect of additional strengthening of hip abductor and lateral rotator muscles in patellofemoral pain syndrome: A randomized controlled pilot study. Clin Rehabil. 2008 Dec;22(12):1051-60.

144. Thomson C, Krouwel O, Kuisma R, Hebron C. The outcome of hip exercise in patellofemoral pain: A systematic review. Man Ther. 2016 Dec;26:1-30.

145. Khayambashi K, Mohammadkhani Z, Ghaznavi K, Lyle MA, Powers CM. The effects of isolated hip abductor and external rotator muscle strengthening on pain, health status, and hip strength in females with patellofemoral pain: A randomized controlled trial. J Orthop Sports Phys Ther. 2012 Jan;42(1):22-9.

146. Kountouris A, Cook J. Rehabilitation of achilles and patellar tendinopathies. Best Pract Res Clin Rheumatol. 2007 Apr;21(2):295-316.

147. Kamonseki DH, Goncalves GA, Yi LC, Junior IL. Effect of stretching with and without muscle strengthening exercises for the foot and hip in patients with plantar fasciitis: A randomized controlled single-blind clinical trial. Man Ther. 2016 Jun;23:76-82. 
148. Santos BD, Correa LA, Teixeira Santos L, Filho NA, Lemos T, Nogueira LA. Combination of hip strengthening and manipulative therapy for the treatment of plantar fasciitis: A case report. J Chiropr Med. 2016 Dec;15(4):310-3.

149. Lee JH, Park JH, Jang WY. The effects of hip strengthening exercises in a patient with plantar fasciitis: A case report. Medicine (Baltimore). 2019 Jun;98(26):e16258.

150. Barton CJ, Levinger $P$, Crossley KM, Webster KE, Menz HB. The relationship between rearfoot, tibial and hip kinematics in individuals with patellofemoral pain syndrome. Clin Biomech (Bristol, Avon). 2012 Aug;27(7):702-5.

151. Khamis S, Yizhar Z. Effect of feet hyperpronation on pelvic alignment in a standing position. Gait Posture. 2007 Jan;25(1):127-34.

152. Powers CM. The influence of altered lower-extremity kinematics on patellofemoral joint dysfunction: A theoretical perspective. J Orthop Sports Phys Ther. 2003 Nov;33(11):639-46.

153. Beeson P. Plantar fasciopathy: Revisiting the risk factors. Foot Ankle Surg. 2014 Sep;20(3):160-5.

154. Martin RL, Davenport TE, Reischl SF, McPoil TG, Matheson JW, Wukich DK, et al. Heel pain-plantar fasciitis: Revision 2014. J Orthop Sports Phys Ther. 2014 Nov;44(11):A1-33.

155. McPoil TG, Martin RL, Cornwall MW, Wukich DK, Irrgang JJ, Godges JJ. Heel pain--plantar fasciitis: Clinical practice guildelines linked to the international classification of function, disability, and health from the orthopaedic section of the american physical therapy association. J Orthop Sports Phys Ther. 2008 Apr;38(4):A1-A18.

156. Bolivar YA, Munuera PV, Padillo JP. Relationship between tightness of the posterior muscles of the lower limb and plantar fasciitis. Foot Ankle Int. 2013 Jan;34(1):42-8. 
157. Labovitz JM, Yu J, Kim C. The role of hamstring tightness in plantar fasciitis. Foot Ankle Spec. 2011 Jun;4(3):141-4.

158. Harty J, Soffe K, O'Toole G, Stephens MM. The role of hamstring tightness in plantar fasciitis. Foot Ankle Int. 2005 Dec;26(12):1089-92.

159. Dolak KL, Silkman C, Medina McKeon J, Hosey RG, Lattermann C, Uhl TL. Hip strengthening prior to functional exercises reduces pain sooner than quadriceps strengthening in females with patellofemoral pain syndrome: A randomized clinical trial. J Orthop Sports Phys Ther. 2011 Aug;41(8):560-70.

160. Snyder KR, Earl JE, O'Connor KM, Ebersole KT. Resistance training is accompanied by increases in hip strength and changes in lower extremity biomechanics during running. Clin Biomech (Bristol, Avon). 2009 Jan;24(1):2634.

161. Fukuda TY, Rossetto FM, Magalhaes E, Bryk FF, Lucareli PR, de Almeida Aparecida Carvalho N. Short-term effects of hip abductors and lateral rotators strengthening in females with patellofemoral pain syndrome: A randomized controlled clinical trial. J Orthop Sports Phys Ther. 2010 Nov;40(11):736-42.

162. Wainner RS, Whitman JM, Cleland JA, Flynn TW. Regional interdependence: A musculoskeletal examination model whose time has come. J Orthop Sports Phys Ther. 2007 Nov;37(11):658-60.

163. Komura T, Prokopow $\mathrm{P}$, Nagano A. Evaluation of the influence of muscle deactivation on other muscles and joints during gait motion. J Biomech. 2004 Apr;37(4):425-36.

164. Goom TS, Malliaras P, Reiman MP, Purdam CR. Proximal hamstring tendinopathy: Clinical aspects of assessment and management. J Orthop Sports Phys Ther. 2016 Jun;46(6):483-93.

165. Zwerver J, Hartgens F, Verhagen E, van der Worp H, van den Akker-Scheek I, Diercks RL. No effect of extracorporeal shockwave therapy on patellar tendinopathy in jumping athletes during the competitive season: A randomized clinical trial. Am J Sports Med. 2011 Jun;39(6):1191-9. 
166. Thompson RC. Managing plantar fasciopathy and tendinopathy through conditioning and load monitoring within elite sport. J. Aust. Strength Cond. $2017 ; 25(5) ; 85-103$.

167. Morgan S, Janse van Vuuren EC, Coetzee F. Patellar tendinopathy: a rehabilitation intervention in elite rugby union players. SAJR SPER. $2018 ; 40(2): 129-142$.

168. Cook JL. Ten treatments to avoid in patients with lower limb tendon pain. $\mathrm{Br}$ J Sports Med. 2018 Jul;52(14):882,2018-099045. Epub 2018 Feb 23.

169. Rudavsky A, Cook J. Physiotherapy management of patellar tendinopathy (jumper's knee). J Physiother. 2014 Sep;60(3):122-9.

170. Scattone Silva R, Ferreira AL, Nakagawa TH, Santos JE, Serrao FV. Rehabilitation of patellar tendinopathy using hip extensor strengthening and landing-strategy modification: Case report with 6-month follow-up. J Orthop Sports Phys Ther. 2015 Nov;45(11):899-909.

171. Stasinopoulos D, Malliaras P. Is the heavy slow resistance program effective for all patients with tendinopathy and effective for all its sites? J Sports Med Phys Fitness. 2016 Nov;56(11):1430-1.

172. Mendonca LM, Bittencourt NFN, Alves LEM, Resende RA, Serrao FV. Interventions used for rehabilitation and prevention of patellar tendinopathy in athletes: A survey of brazilian sports physical therapists. Braz J Phys Ther. 2020 Jan - Feb;24(1):46-53.

173. Powers CM. The influence of abnormal hip mechanics on knee injury: $A$ biomechanical perspective. J Orthop Sports Phys Ther. 2010 Feb;40(2):42-51.

174. Taube W, Leukel C, Lauber B, Gollhofer A. The drop height determines neuromuscular adaptations and changes in jump performance in stretchshortening cycle training. Scand J Med Sci Sports. 2012 Oct;22(5):671-83.

175. Foure A, Nordez A, Cornu C. Plyometric training effects on achilles tendon stiffness and dissipative properties. J Appl Physiol (1985). 2010 Sep;109(3):84954. 
176. Kubo K, Morimoto M, Komuro T, Yata H, Tsunoda N, Kanehisa H, et al. Effects of plyometric and weight training on muscle-tendon complex and jump performance. Med Sci Sports Exerc. 2007 Oct;39(10):1801-10.

177. Spurrs RW, Murphy AJ, Watsford ML. The effect of plyometric training on distance running performance. Eur J Appl Physiol. 2003 Mar;89(1):1-7.

178. Child S, Bryant AL, Clark RA, Crossley KM. Mechanical properties of the achilles tendon aponeurosis are altered in athletes with achilles tendinopathy. Am J Sports Med. 2010 Sep;38(9):1885-93.

179. Gajhede-Knudsen M, Ekstrand J, Magnusson H, Maffulli N. Recurrence of achilles tendon injuries in elite male football players is more common after early return to play: An 11-year follow-up of the UEFA champions league injury study. $\mathrm{Br}$ J Sports Med. 2013 Aug;47(12):763-8.

180. McAuliffe S, Tabuena A, McCreesh K, O'Keeffe M, Hurley J, Comyns T, et al. Altered strength profile in achilles tendinopathy: A systematic review and metaanalysis. J Athl Train. 2019 Aug;54(8):889-900.

181. Beattie K, Kenny IC, Lyons M, Carson BP. The effect of strength training on performance in endurance athletes. Sports Med. 2014 Jun;44(6):845-65.

182. Wang HK, Lin KH, Su SC, Shih TT, Huang YC. Effects of tendon viscoelasticity in achilles tendinosis on explosive performance and clinical severity in athletes. Scand J Med Sci Sports. 2012 Dec;22(6):e147-55.

183. Maquirriain J. Leg stiffness changes in athletes with achilles tendinopathy. Int J Sports Med. 2012 Jul;33(7):567-71.

184. Chmielewski TL, Myer GD, Kauffman D, Tillman SM. Plyometric exercise in the rehabilitation of athletes: Physiological responses and clinical application. J Orthop Sports Phys Ther. 2006 May;36(5):308-19.

185. Huffer D, Hing W, Newton R, Clair M. Strength training for plantar fasciitis and the intrinsic foot musculature: A systematic review. Phys Ther Sport. 2017 Mar;24:44-52. 
186. van der Plas $A$, de Jonge $S$, de Vos RJ, van der Heide HJ, Verhaar JA, Weir A, et al. A 5-year follow-up study of alfredson's heel-drop exercise programme in chronic midportion achilles tendinopathy. Br J Sports Med. 2012 Mar;46(3):2148.

187. Allison GT, Purdam C. Eccentric loading for achilles tendinopathy-strengthening or stretching? Br J Sports Med. 2009 Apr;43(4):276-9.

188. Mersmann F, Bohm S, Arampatzis A. Imbalances in the development of muscle and tendon as risk factor for tendinopathies in youth athletes: A review of current evidence and concepts of prevention. Front Physiol. 2017 Dec 1;8:987.

189. Mersmann F, Pentidis N, Tsai MS, Schroll A, Arampatzis A. Patellar tendon strain associates to tendon structural abnormalities in adolescent athletes. Front Physiol. 2019 Aug 2;10:963.

190. Sancho I, Morrissey D, Willy RW, Barton C, Malliaras P. Education and exercise supplemented by a pain-guided hopping intervention for male recreational runners with midportion achilles tendinopathy: A single cohort feasibility study. Phys Ther Sport. 2019 Nov;40:107-16.

191. Sancho I, Malliaras P, Barton C, Willy RW, Morrissey D. Biomechanical alterations in individuals with achilles tendinopathy during running and hopping: A systematic review with meta-analysis. Gait Posture. 2019 Sep;73:189-201.

192. Jones MD, Valenzuela T, Booth J, Taylor JL, Barry BK. Explicit education about exercise-induced hypoalgesia influences pain responses to acute exercise in healthy adults: A randomized controlled trial. J Pain. 2017 Nov;18(11):1409-16.

193. Harries SK, Lubans DR, Callister R. Systematic review and meta-analysis of linear and undulating periodized resistance training programs on muscular strength. J Strength Cond Res. 2015 Apr;29(4):1113-25.

194. Conlon JA, Newton RU, Tufano JJ, Banyard HG, Hopper AJ, Ridge AJ, et al. Periodization strategies in older adults: Impact on physical function and health. Med Sci Sports Exerc. 2016 Dec;48(12):2426-36. 
195. Kiely J. Periodization theory: Confronting an inconvenient truth. Sports Med. 2018 Apr;48(4):753-64.

196. Issurin V. Block periodization versus traditional training theory: A review. J Sports Med Phys Fitness. 2008 Mar;48(1):65-75.

197. Issurin VB. New horizons for the methodology and physiology of training periodization. Sports Med. 2010 Mar 1;40(3):189-206.

198. Bartolomei S, Hoffman JR, Merni F, Stout JR. A comparison of traditional and block periodized strength training programs in trained athletes. J Strength Cond Res. 2014 Apr;28(4):990-7.

199. Storen O, Helgerud J, Stoa EM, Hoff J. Maximal strength training improves running economy in distance runners. Med Sci Sports Exerc. 2008 Jun;40(6): 1087-92.

200. Wisloff U, Castagna C, Helgerud J, Jones R, Hoff J. Strong correlation of maximal squat strength with sprint performance and vertical jump height in elite soccer players. Br J Sports Med. 2004 Jun;38(3):285-8.

201. Stone MH, Sands WA, Carlock J, Callan S, Dickie D, Daigle K, et al. The importance of isometric maximum strength and peak rate-of-force development in sprint cycling. J Strength Cond Res. 2004 Nov;18(4):878-84.

202. Booth J, Moseley GL, Schiltenwolf M, Cashin A, Davies M, Hubscher M. Exercise for chronic musculoskeletal pain: A biopsychosocial approach. Musculoskeletal Care. 2017 Dec;15(4):413-21.

203. Babatunde OO, Jordan JL, Van der Windt DA, Hill JC, Foster NE, Protheroe J. Effective treatment options for musculoskeletal pain in primary care: A systematic overview of current evidence. PLoS One. 2017 Jun 22;12(6):e0178621.

204. Ladlow P, Conway D, Hayhurst D, Suffield C, Cassidy RP, Coppack RJ. Integration of strength training into UK defence rehabilitation practice: Current trends and future challenges. BMJ Mil Health. 2020 Oct 21. 
205. Hoover DL, VanWye WR, Judge LW. Periodization and physical therapy: Bridging the gap between training and rehabilitation. Phys Ther Sport. 2016 Mar;18:1-20.

206. Reiman MP, Lorenz DS. Integration of strength and conditioning principles into a rehabilitation program. Int J Sports Phys Ther. 2011 Sep;6(3):241-53.

207. Lorenz DS, Reiman MP. Performance enhancement in the terminal phases of rehabilitation. Sports Health. 2011 Sep;3(5):470-80.

208. Lorenz DS, Reiman MP, Walker JC. Periodization: Current review and suggested implementation for athletic rehabilitation. Sports Health. 2010 Nov;2(6):509-18.

209. Mann TN, Lamberts RP, Lambert MI. High responders and low responders: Factors associated with individual variation in response to standardized training. Sports Med. 2014 Aug;44(8):1113-24.

210. Costa J, Figueiredo P, Nakamura F, Rago V, Rebelo A, Brito J. Intra-individual variability of sleep and nocturnal cardiac autonomic activity in elite female soccer players during an international tournament. PLoS One. 2019 Sep $17 ; 14(9): \mathrm{e} 0218635$.

211. Timmons JA. Variability in training-induced skeletal muscle adaptation. J Appl Physiol (1985). 2011 Mar;110(3):846-53.

212. Fisher J, Steele J, Smith D. High- and low-load resistance training: Interpretation and practical application of current research findings. Sports Med. 2017 Mar;47(3):393-400.

213. Zourdos MC, Jo E, Khamoui AV, Lee SR, Park BS, Ormsbee MJ, et al. Modified daily undulating periodization model produces greater performance than a traditional configuration in powerlifters. J Strength Cond Res. 2016 Mar;30(3):784-91.

214. Rauch JT, Ugrinowitsch C, Barakat CI, Alvarez MR, Brummert DL, Aube DW, et al. Auto-regulated exercise selection training regimen produces small increases 
in lean body mass and maximal strength adaptations in strength-trained individuals. J Strength Cond Res. 2020 Apr;34(4):1133-40.

215. Kiely J. Periodization paradigms in the 21st century: Evidence-led or tradition-driven? Int J Sports Physiol Perform. 2012 Sep;7(3):242-50.

216. Borresen J, Lambert MI. The quantification of training load, the training response and the effect on performance. Sports Med. 2009;39(9):779-95.

217. Jones N, Kiely J, Suraci B, Collins DJ, de Lorenzo D, Pickering C, et al. A genetic-based algorithm for personalized resistance training. Biol Sport. 2016 Jun;33(2):117-26.

218. DELORME TL, WEST FE, SHRIBER WJ. Influence of progressive resistance exercises on knee function following femoral fractures. J Bone Joint Surg Am. 1950 Oct;32 A(4):910-24.

219. Knight KL. Knee rehabilitation by the daily adjustable progressive resistive exercise technique. Am J Sports Med. 1979 Nov-Dec;7(6):336-7.

220. Knight KL. Quadriceps strengthening with the DAPRE technique: Case studies with neurological implications. J Orthop Sports Phys Ther. 1990;12(2):66-71.

221. Siff MC. Supertraining. Denver: Supertraining Institute; 2000.

222. Cunanan AJ, DeWeese BH, Wagle JP, Carroll KM, Sausaman R, Hornsby WG,3rd, et al. The general adaptation syndrome: A foundation for the concept of periodization. Sports Med. 2018 Apr;48(4):787-97.

223. Horschig AD, Neff TE, Serrano AJ. Utilization of autoregulatory progressive resistance exercise in transitional rehabilitation periodization of a high school football-player following anterior cruciate ligament reconstruction: A case report. Int J Sports Phys Ther. 2014 Oct;9(5):691-8.

224. Wilson ME. The daily adjustable progressive resistance exercise system: getting reacquainted with an old friend. Strength Cond J. 2008;30(2):76-8. 
225. Brumitt J, Cuddeford T. Current concepts of muscle and tendon adaptation to strength and conditioning. Int J Sports Phys Ther. 2015 Nov;10(6):748-59.

226. Lorenz D, Morrison S. Current concepts in periodization of strength and conditioning for the sports physical therapist. Int J Sports Phys Ther. 2015 Nov;10(6):734-47.

227. Rhea MR, Hunter RL, Hunter TJ. Competition modeling of american football: Observational data and implications for high school, collegiate, and professional player conditioning. J Strength Cond Res. 2006 Feb;20(1):58-61.

228. McNamara JM, Stearne DJ. Flexible nonlinear periodization in a beginner college weight training class. J Strength Cond Res. 2010 Jan;24(1):17-22.

229. Folland JP, Williams AG. The adaptations to strength training : Morphological and neurological contributions to increased strength. Sports Med. $2007 ; 37(2): 145-68$.

230. Ardali G. A daily adjustable progressive resistance exercise protocol and functional training to increase quadriceps muscle strength and functional performance in an elderly homebound patient following a total knee arthroplasty. Physiother Theory Pract. 2014 May;30(4):287-97.

231. Klemp A, Dolan C, Quiles JM, Blanco R, Zoeller RF, Graves BS, et al. Volumeequated high- and low-repetition daily undulating programming strategies produce similar hypertrophy and strength adaptations. Appl Physiol Nutr Metab. 2016 Jul;41(7):699-705.

232. Goessler KF, Polito MD. Effect of fixed and self-suggested rest intervals between sets of resistance exercise on post- exercise cardiovascular behavior. Rev Bras Cineantropom Desempenho Hum. 2013;15(4):467-75.

233. Henselmans $M$, Schoenfeld $B J$. The effect of inter-set rest intervals on resistance exercise-induced muscle hypertrophy. Sports Med. 2014 Dec;44(12):1635-43. 
234. Kraft JA, Green JM, Gast TM. Work distribution influences session ratings of perceived exertion response during resistance exercise matched for total volume. J Strength Cond Res. 2014 Jul;28(7):2042-6.

235. Lins-Filho Ode L, Robertson RJ, Farah BQ, Rodrigues SL, Cyrino ES, Ritti-Dias RM. Effects of exercise intensity on rating of perceived exertion during a multipleset resistance exercise session. J Strength Cond Res. 2012 Feb;26(2):466-72.

236. Day ML, McGuigan MR, Brice G, Foster C. Monitoring exercise intensity during resistance training using the session RPE scale. J Strength Cond Res. 2004 May;18(2):353-8.

237. Duncan MJ, Al-Nakeeb Y, Scurr J. Perceived exertion is related to muscle activity during leg extension exercise. Res Sports Med. 2006 Jul-Sep;14(3):17989.

238. Gearhart RF,Jr, Lagally KM, Riechman SE, Andrews RD, Robertson RJ. Strength tracking using the OMNI resistance exercise scale in older men and women. J Strength Cond Res. 2009 May;23(3):1011-5.

239. Tiggemann $\mathrm{CL}$, Korzenowski AL, Brentano $\mathrm{MA}$, Tartaruga $\mathrm{MP}$, Alberton $\mathrm{CL}$, Kruel LF. Perceived exertion in different strength exercise loads in sedentary, active, and trained adults. J Strength Cond Res. 2010 Aug;24(8):2032-41.

240. Testa M, Noakes TD, Desgorces FD. Training state improves the relationship between rating of perceived exertion and relative exercise volume during resistance exercises. J Strength Cond Res. 2012 Nov;26(11):2990-6.

241. McGuigan MR, Al Dayel A, Tod D, Foster C, Newton RU, Pettigrew S. Use of session rating of perceived exertion for monitoring resistance exercise in children who are overweight or obese. Pediatr Exerc Sci. 2008 Aug;20(3):333-41.

242. Haff G, Triplett NT. Essentials of strength training and conditioning. Fourth edition. Champaign, IL: Human Kinetics. 2016. 
243. American College of Sports Medicine. American college of sports medicine position stand. progression models in resistance training for healthy adults. Med Sci Sports Exerc. 2009 Mar;41(3):687-708.

244. Drew BT, Conaghan PG, Smith TO, Selfe J, Redmond AC. The effect of targeted treatment on people with patellofemoral pain: A pragmatic, randomised controlled feasibility study. BMC Musculoskelet Disord. 2017 Aug $4 ; 18(1): 338,017-1698-7$.

245. Tuchscherer $M$. The reactive training manual: developing your own custom training program for powerlifting: reactive training systems; Self-published. 2008.

246. Zourdos MC, Klemp A, Dolan C, Quiles JM, Schau KA, Jo E, et al. Novel resistance training-specific rating of perceived exertion scale measuring repetitions in reserve. J Strength Cond Res. 2016 Jan;30(1):267-75.

247. Shimano T, Kraemer WJ, Spiering BA, Volek JS, Hatfield DL, Silvestre R, et al. Relationship between the number of repetitions and selected percentages of one repetition maximum in free weight exercises in trained and untrained men. J Strength Cond Res. 2006 Nov;20(4):819-23.

248. Pritchett RC, Green JM, Wickwire PJ, Kovacs MS. Acute and session RPE responses during resistance training: Bouts to failure at $60 \%$ and $90 \%$ of 1 RM. South African Journal of Sports Medicine. 2009;21(1).

249. Hackett DA, Johnson NA, Halaki M, Chow CM. A novel scale to assess resistance-exercise effort. J Sports Sci. 2012;30(13):1405-13.

250. Helms ER, Cronin J, Storey A, Zourdos MC. Application of the repetitions in reserve-based rating of perceived exertion scale for resistance training. Strength Cond J. 2016 Aug;38(4):42-9.

251. Hackett DA, Cobley SP, Davies TB, Michael SW, Halaki M. Accuracy in estimating repetitions to failure during resistance exercise. J Strength Cond Res. 2017 Aug;31(8):2162-8. 
252. Mansfield SK, Peiffer JJ, Hughes LJ, Scott BR. Estimating repetitions in reserve for resistance exercise: An analysis of factors which impact on prediction accuracy. J Strength Cond Res. 2020 Aug 31.

253. Fairman CM, Zourdos MC, Helms ER, Focht BC. A scientific rationale to improve resistance training prescription in exercise oncology. Sports Med. 2017 Aug;47(8):1457-65.

254. Graham T, Cleather DJ. Autoregulation by "repetitions in reserve" leads to greater improvements in strength over a 12-week training program than fixed loading. J Strength Cond Res. 2019 Apr 17.

255. Shattock K, Tee JC. Autoregulation in resistance training: A comparison of subjective versus objective methods. J Strength Cond Res. 2020 Feb 13.

256. Nevin J. Autoregulated resistance training: does velocity-based training represent the future? Strength Cond J. 2019;41(4):34-9.

257. Dorrell HF, Moore JM, Smith MF, Gee TI. Validity and reliability of a linear positional transducer across commonly practised resistance training exercises. J Sports Sci. 2019 Jan;37(1):67-73.

258. Gonzalez-Badillo JJ, Marques, MC, Sanchez-Medina L. The importance of movement velocity as a measure to control resistance training intensity. J Jum Kinet. $2011 ; 29 A ; 15-19$.

259. Jovanovic M, Jukic I. Within-unit reliability and between-units agreement of the commercially available linear position transducer and barbell-mounted inertial sensor to measure movement velocity. J Strength Cond Res. 2020 Oct 9.

260. Banyard HG, Tufano JJ, Weakley JJS, Wu S, Jukic I, Nosaka K. Superior changes in jump, sprint, and change-of-direction performance but not maximal strength following 6 weeks of velocity-based training compared with 1-repetitionmaximum percentage-based training. Int J Sports Physiol Perform. 2020 Sep 1:111. 
261. Lahti J, Jimenez-Reyes $P$, Cross MR, Samozino P, Chassaing P, Simond-Cote $B$, et al. Individual sprint force-velocity profile adaptations to in-season assisted and resisted velocity-based training in professional rugby. Sports (Basel). 2020 May 25;8(5):10.3390/sports8050074.

262. Perez-Castilla A, Jimenez-Alonso A, Cepero M, Miras-Moreno S, Rojas FJ, Garcia-Ramos A. Velocity performance feedback during ballistic training: Which is the optimal frequency of feedback administration? Motor Control. 2020 Sep 30:114.

263. Martinez-Cava A, Hernandez-Belmonte A, Courel-Ibanez J, Moran-Navarro R, Gonzalez-Badillo JJ, Pallares JG. Reliability of technologies to measure the barbell velocity: Implications for monitoring resistance training. PLoS One. 2020 Jun $10 ; 15(6)$ :e0232465.

264. Sindiani M, Lazarus A, Iacono AD, Halperin I. Perception of changes in bar velocity in resistance training: Accuracy levels within and between exercises. Physiol Behav. 2020 Oct 1;224:113025.

265. Suarez-Arrones L, Nunez FJ, Lara-Lopez P, Di Salvo V, Mendez-Villanueva A. Inertial flywheel knee- and hip-dominant hamstring strength exercises in professional soccer players: Muscle use and velocity-based (mechanical) eccentric overload. PLoS One. 2020 Oct 2;15(10):e0239977.

266. Tsoukos A, Brown LE, Terzis G, Veligekas P, Bogdanis GC. Potentiation of bench press throw performance using a heavy load and velocity-based repetition control. J Strength Cond Res. 2020 May 8.

267. Kawamori N, Rossi SJ, Justice BD, Haff EE, Pistilli EE, O'Bryant HS, et al. Peak force and rate of force development during isometric and dynamic mid-thigh clean pulls performed at various intensities. J Strength Cond Res. 2006 Aug;20(3):483-91.

268. Dorrell HF, Smith MF, Gee TI. Comparison of velocity-based and traditional percentage-based loading methods on maximal strength and power adaptations. J Strength Cond Res. 2020 Jan;34(1):46-53. 
269. Littlewood C, Malliaras P, Mawson S, May S, Walters S. Development of a self-managed loaded exercise programme for rotator cuff tendinopathy. Physiotherapy. 2013 Dec;99(4):358-62.

270. Barlow J, Wright C, Sheasby J, Turner A, Hainsworth J. Self-management approaches for people with chronic conditions: A review. Patient Educ Couns. 2002 Oct -Nov;48(2):177-87.

271. Holman H, Lorig K. Patient self-management: A key to effectiveness and efficiency in care of chronic disease. Public Health Rep. 2004 May-Jun;119(3):23943.

272. Peek K, Sanson-Fisher R, Mackenzie L, Carey M. Interventions to aid patient adherence to physiotherapist prescribed self-management strategies: $A$ systematic review. Physiotherapy. 2016 Jun;102(2):127-35.

273. Rathleff MS, Thorborg K, Rode LA, McGirr KA, Sorensen AS, Bogild A, et al. Adherence to commonly prescribed, home-based strength training exercises for the lower extremity can be objectively monitored using the bandcizer. J Strength Cond Res. 2015 Mar;29(3):627-36

274. Osteras B, Osteras $H$, Torstensen TA, Vasseljen O. Dose-response effects of medical exercise therapy in patients with patellofemoral pain syndrome: $A$ randomised controlled clinical trial. Physiotherapy. 2013 Jun;99(2):126-31.

275. Burd NA, Andrews RJ, West DW, Little JP, Cochran AJ, Hector AJ, et al. Muscle time under tension during resistance exercise stimulates differential muscle protein sub-fractional synthetic responses in men. J Physiol. 2012 Jan $15 ; 590(2): 351-62$

276. Faber M, Andersen MH, Sevel C, Thorborg K, Bandholm T, Rathleff M. The majority are not performing home-exercises correctly two weeks after their initial instruction-an assessor-blinded study. Peer]. 2015 Jul 21;3:e1102.

277. Rathleff CR, Bandholm T, Spaich EG, Jorgensen M, Andreasen J. Unsupervised progressive elastic band exercises for frail geriatric inpatients objectively monitored by new exercise-integrated technology-a feasibility trial 
with an embedded qualitative study. Pilot Feasibility Stud. 2017 Nov 13;3:56,0170202-3. eCollection 2017.

278. McGirr K, Harring SI, Kennedy TS, Pedersen MF, Hirata RP, Thorborg K, et al. An elastic exercise band mounted with a bandcizer can differentiate between commonly prescribed home exercises for the shoulder. Int J Sports Phys Ther. 2015 Jun;10(3):332-40.

279. Riel H, Matthews M, Vicenzino B, Bandholm T, Thorborg K, Rathleff MS. Efficacy of live feedback to improve objectively monitored compliance to prescribed, home-based, exercise therapy-dosage in 15 to 19 year old adolescents with patellofemoral pain- a study protocol of a randomized controlled superiority trial (the XRCISE-AS-INSTRUcted-1 trial). BMC Musculoskelet Disord. 2016 Jun 2;17:242,016-1103-y.

280. Hale ED, Treharne GJ, Kitas GD. The common-sense model of self-regulation of health and illness: How can we use it to understand and respond to our patients' needs? Rheumatology (Oxford). 2007 Jun;46(6):904-6.

281. McAndrew LM, Musumeci-Szabo TJ, Mora PA, Vileikyte L, Burns E, Halm EA, et al. Using the common sense model to design interventions for the prevention and management of chronic illness threats: From description to process. $\mathrm{Br} \mathrm{J}$ Health Psychol. 2008 May;13(Pt 2):195-204.

282. Phillips LA, Leventhal H, Leventhal EA. Physicians' communication of the common-sense self-regulation model results in greater reported adherence than physicians' use of interpersonal skills. Br J Health Psychol. 2012 May;17(2):24457.

283. Littlewood C, Ashton J, Mawson S, May S, Walters S. A mixed methods study to evaluate the clinical and cost-effectiveness of a self-managed exercise programme versus usual physiotherapy for chronic rotator cuff disorders: Protocol for the SELF study. BMC Musculoskelet Disord. 2012 Apr 30;13:62,2474-13-62.

284. Newman SP. Chronic disease self-management approaches within the complex organisational structure of a health care system. Med J Aust. 2008 Nov 17;189(10 Suppl):S7-8. 
285. Bernhardsson S, Klintberg IH, Wendt GK. Evaluation of an exercise concept focusing on eccentric strength training of the rotator cuff for patients with subacromial impingement syndrome. Clin Rehabil. 2011 Jan;25(1):69-78.

286. Littlewood C, Bateman M, Brown K, Bury J, Mawson S, May S, et al. A selfmanaged single exercise programme versus usual physiotherapy treatment for rotator cuff tendinopathy: A randomised controlled trial (the SELF study). Clin Rehabil. 2016 Jul;30(7):686-96.

287. Holmgren T, Bjornsson Hallgren H, Oberg B, Adolfsson L, Johansson K. Effect of specific exercise strategy on need for surgery in patients with subacromial impingement syndrome: Randomised controlled study. BMJ. 2012 Feb $20 ; 344: e 787$.

288. Petraglia F, Ramazzina I, Costantino C. Plantar fasciitis in athletes: Diagnostic and treatment strategies. A systematic review. Muscles Ligaments Tendons J. 2017 May $10 ; 7(1): 107-18$.

289. Tahririan MA, Motififard M, Tahmasebi MN, Siavashi B. Plantar fasciitis. J Res Med Sci. 2012 Aug;17(8):799-804.

290. Kader D, Saxena A, Movin T, Maffulli N. Achilles tendinopathy: Some aspects of basic science and clinical management. Br J Sports Med. 2002 Aug;36(4):23949.

291. Paavola $M$, Kannus $P$, Jarvinen TA, Khan $K$, Jozsa $L$, Jarvinen $M$. Achilles tendinopathy. J Bone Joint Surg Am. 2002 Nov;84(11):2062-76.

292. Silbernagel KG, Brorsson A, Lundberg $M$. The majority of patients with achilles tendinopathy recover fully when treated with exercise alone: A 5-year follow-up. Am J Sports Med. 2011 Mar;39(3):607-13.

293. Ciolac EG, Rodrigues-da-Silva JM. Resistance training as a tool for preventing and treating musculoskeletal disorders. Sports Med. 2016 Sep;46(9):1239-48. 
294. McLean SM, Burton M, Bradley L, Littlewood C. Interventions for enhancing adherence with physiotherapy: A systematic review. Man Ther. 2010 Dec;15(6):514-21.

295. Jack K, McLean SM, Moffett JK, Gardiner E. Barriers to treatment adherence in physiotherapy outpatient clinics: A systematic review. Man Ther. 2010 Jun;15(3):220-8.

296. Stevens M, Tan CW. Effectiveness of the alfredson protocol compared with a lower repetition-volume protocol for midportion achilles tendinopathy: A randomized controlled trial. J Orthop Sports Phys Ther. 2014 Feb;44(2):59-67.

297. Boren K, Conrey C, Le Coguic J, Paprocki L, Voight M, Robinson TK. Electromyographic analysis of gluteus medius and gluteus maximus during rehabilitation exercises. Int J Sports Phys Ther. 2011 Sep;6(3):206-23. 